\title{
Simulation of fracture healing incorporating mechanoregulation of tissue differentiation and dispersal/proliferation of cells
}

\author{
A. Andreykiv - F. van Keulen • P. J. Prendergast
}

Received: 16 February 2007 / Accepted: 8 October 2007 / Published online: 31 October 2007

(C) Springer-Verlag 2007

\begin{abstract}
Modelling the course of healing of a long bone subjected to loading has been the subject of several investigations. These have succeeded in predicting the differentiation of tissues in the callus in response to a static mechanical load and the diffusion of biological factors. In this paper an approach is presented which includes both mechanoregulation of tissue differentiation and the diffusion and proliferation of cell populations (mesenchymal stem cells, fibroblasts, chondrocytes, and osteoblasts). This is achieved in a three-dimensional poroelastic finite element model which, being poroelastic, can model the effect of the frequency of dynamic loading. Given the number of parameters involved in the simulation, a parameter variation study is reported, and final parameters are selected based on comparison with an in vivo experiment. The model predicts that asymmetric loading creates an asymmetric distribution of tissues in the callus, but only for high bending moments. Furthermore the frequency of loading is predicted to have an effect. In conclusion, a numerical algorithm is presented incorporating both mechanoregulation and evolution of cell populations, and it proves capable of predicting realistic difference in bone healing in a 3D fracture callus.
\end{abstract}

Keywords Bone fracture healing - Tissue differentiation . Finite element method $\cdot$ Mechanobiology $\cdot$ Biophysical stimuli

\footnotetext{
A. Andreykiv $(\varangle) \cdot$ F. van Keulen

Faculty of Mechanical, Maritime and Material Engineering,

Delft University of Technology, Mekelweg 2,

2628 CD Delft, The Netherlands

e-mail: a.andreykiv@tudelft.nl

P. J. Prendergast

Trinity Centre for Bioengineering, School of Engineering,

Trinity College, Dublin, Ireland
}

\section{Introduction}

Bone fracture is a common injury which normally heals without any complications. But in up to $10 \%$ of the cases (Einhorn 1995; Praemer et al. 1999) complications may lead to delayed healing or non-union.

It was shown clinically that mechanical stimulation of the fractured bone can influence the healing process. Many researches clinically investigated a wide range of mechanical factors in order to find optimal mechanical conditions, under which the healing will be successful. Goodship and Kenwright (1985) showed that application of controlled axial micro-movement results in significant improvement of healing as compared to rigid fixation of the osteotomy site. Claes et al. (1995); Claes et al. (1997) and Claes et al. (1998) showed a negative effect of large osteotomy gaps on the healing process. While exploring the influence of the loading applied to the fractured bone, Augat et al. (2003) showed a negative effect of shear movement and Goodship et al. (1998) showed a positive effect of high strain rate on bone healing. In earlier studies, the healing process was mainly quantified by interfragmentary movement, walking stiffness or bone mineral content, while more recent studies also present results on the histology analysis of callus under different loading conditions (for instance, Claes et al. 1998; Le et al. 2001). Other authors managed to develop experimental animal protocols that force the healing process to go into a predefined path, like intramembranous ossification (Thompson et al. 2002).

Despite the progress in experimental techniques it has proven difficult to understand mechanoregulation during fracture healing because it is not possible to isolate the effect of the various mechanical parameters. Computer models, on the contrary, allow accurate simulation of very complicated mechanical and biological environments. Calculating local stresses and strains in the fractured bone by finite element 
analysis, Claes and Heigele (1999) successfully predicted course and type of fracture healing. Gardner et al. (2000) investigated the healing process in long bone fractures and in oblique fractures. Ament and Hofer (2000) went one step further by simulating the kinetics of the healing process using linear elastic FE simulation in combination with their fuzzy logic model. Lacroix and Prendergast (2002a) and Lacroix et al. (2002) assumed a poroelastic nature of the callus and simulated dispersal of the mesenchymal cell as a diffusion process. They assumed that differentiation of the migrating mesenchymal cells into bone, cartilage and fibrous tissue forming cells will be regulated by tissue's shear strain and velocity of the fluid inside the callus. This approach allowed successful prediction of the osteotomy gap size effect on the healing process. Later, Lacroix and Prendergast (2002b) performed a 3D healing simulation based on the real geometry of a fractured bone with an external fixator. Bailon-Plaza and van der Meulen (2001) were the first who introduced a very advanced biological component in their numerical modelling, which included simulation of cell migration, proliferation and differentiation under the influence of growth factors, as well as production and resorption of corresponding tissues. However, this pioneering work did not account for mechanoregulation of the healing process. But, in their next paper (Bailon-Plaza and van der Meulen 2003) the added mechanics helped to show the effect of the different timing in loading application. However, as it employed a 2D finite difference approach and was limited to elasticity, it was not able to predict the effect of the strain rate as was shown by Goodship et al. (1998) (the clinical result Bailon-Plaza and van der Meulen 2003 used for the validation of their model). It is the complexity of their biological model, which probably did not allow them to easily implement it in a finite element model.

In the current work we aim at developing a model that would account for the major processes during the bone healing, while, at the same time, allowing easy implementation in a finite element model. The latter makes the model applicable for the study on realistic clinical cases, i.e., complex geometries, where patient-specific simulations could be contemplated. The model was calibrated and validated using in vivo experiments reported in literature. The application of the model examines the effect of bending and loading frequency on the healing process.

\section{Methods}

\subsection{Tissue differentiation model inside the callus}

Bone fracture healing can be classified as primary and secondary. Primary healing takes place in case of high mechanical stability and small gap sizes. In this case, bone fragments get connected by direct bone remodelling in the

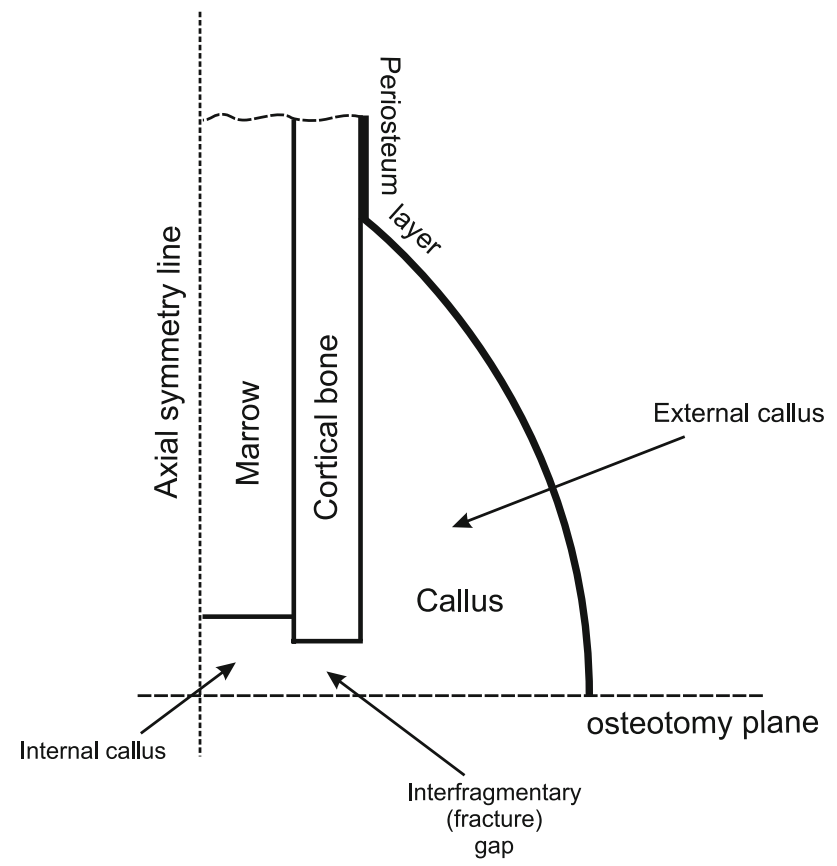

Fig. 1 Schematic description of the osteotomized (fractured) bone region

space between the bone fragments with formation of small or no fracture callus (Perren 1979). However, in most cases, the healing goes via a secondary path. Secondary healing starts with inflammation, when blood, that comes from the ruptured blood vessels, causes formation of hemorrhage (Einhorn 1998). Next, mesenchymal cells, that originate from periosteum (see Fig. 1 for explanation), and marrow stromal cells migrate into the callus and proliferate. Depending on the local mechanical and biological environment, these cell differentiate either into osteoblasts, bone forming cells, chondrocytes, cartilage forming cells or fibroblasts, the cells that produce fibrous tissue.

Again, depending on the mechanical and biological environment, these cells can migrate, proliferate and produce corresponding tissues. Mesenchymal cells that reach the fracture gap often differentiate into fibroblasts, forming fibrous tissue. Bone formation starts in the external part of the callus near original cortical bone via intramembranous ossification while chondrogenesis initiates near the periosteum layer, but closer to the osteotomy plane. As healing progresses, the intramembranous ossification front advances towards the osteotomy plane. Next, the ossification of the cartilage callus begins, a process known as endochondral ossification. Endochondral ossification finalizes the reparative stage of the healing. During this process chondrocytes are replaced by osteoblasts that produce bone matrix. Endochondral ossification continues until all the cartilage has been replaced by bone and bone entirely bridges the fracture gap. The last stage of the 
healing is restoration of the original geometry of the bone by resorption of the external callus.

In this study we present a model of secondary bone healing. We study the same geometry of the fracture callus as Lacroix and Prendergast (2002a) which is assumed constant during the simulation. The simulated interfragmentary gap size was $3 \mathrm{~mm}$. The model consists of the two main components: biological and mechanical. The biological component of the model allows simulation of cellular processes, namely cell migration, proliferation, differentiation, tissue deposition and replacement. The mechanical component of the model calculates the mechanical stimuli that influence the cellular processes. We assume that all cell types have the same critical "saturated" density value and the presented cell densities are normalized with respect to that saturated density. The presented tissue densities are quantified as volume fractions of the corresponding tissues. Subsequently, the sum of all tissue densities is equal to one. Initial and boundary conditions are: (a) the callus is filled with granulation tissue and all the cell and other tissue densities are zero; (b) mesenchymal cells originate from the periosteum layer and the bone marrow, hence the mesenchymal cell density at those areas are kept at the highest saturated level (unity in terms of the normalized values) for a period of time which is treated later as a parameter of the model; (c) influx of fibroblasts, chondrocytes and osteoblasts from the boundary of the callus is set to zero (prohibited). Cell differentiation, proliferation and tissue production are regulated by tissue shear strain and interstitial fluid velocity, as was proposed by Prendergast et al. (1997). Evolution of mesenchymal and fibroblast cell densities are described by equations:

$$
\begin{aligned}
\frac{\mathrm{d} c_{m}}{\mathrm{~d} t}= & D_{m} \nabla^{2} c_{m}+P_{m}\left(1-c_{\mathrm{tot}}\right) c_{m}-F_{f}\left(1-c_{f}\right) c_{m} \\
& -F_{c}\left(1-c_{c}\right) c_{m}-F_{b}\left(1-c_{b}\right) c_{m}, \\
\frac{\mathrm{d} c_{f}}{\mathrm{~d} t}= & D_{f} \nabla^{2} c_{f}+P_{f}\left(1-c_{\mathrm{tot}}\right) c_{f}+F_{f}\left(1-c_{f}\right) c_{m} \\
& -F_{c}\left(1-c_{c}\right) c_{f}-F_{b}\left(1-c_{b}\right) c_{f} .
\end{aligned}
$$

Here $c_{m}, c_{f}, c_{c}$ and $c_{b}$ are mesenchymal, fibroblast, chondrocyte and osteoblast normalized cells densities, $D_{m}$ and $D_{f}$ are the corresponding diffusion coefficients. The diffusion coefficients are assumed to depend on bone $\left(m_{b}\right)$ and cartilage $\left(m_{c}\right)$ volume fractions in the following way: $D_{i}=$ $D_{i_{0}}\left(1-m_{c}-m_{b}\right), i=m, f . D_{m_{0}}$ and $D_{f_{0}}$ are the initial diffusion coefficients. The total cell density is $c_{\text {tot }}=c_{m}+$ $c_{f}+c_{c}+c_{b}$. Values $P_{m}$ and $P_{f}$ are proliferation rates, that also depend on cartilage and bone volume fractions: $P_{i}=$ $P_{i_{0}}\left(1-m_{c}-m_{b}\right), i=m, f$. Values $P_{m_{0}}$ and $P_{f_{0}}$ are the initial proliferation rates that depend on the mechanical stimulus (see Appendix 4) introduced by Prendergast et al. (1997): $S=\frac{\gamma}{a}+\frac{v}{b}$. Values $\gamma$ and $v$ are maximal shear strain and interstitial fluid velocity, respectively, and $a=0.0375$ and $b=3 \mu \mathrm{m} \mathrm{s}^{-1}$ are the constants, determined by Huiskes et al. (1997). According to Prendergast et al. (1997), if $S$ is smaller than some threshold $S_{\min }$, then the mechanical environment is favorable for osteoblast differentiation and bone matrix deposition. Moderate magnitudes of the stimulus $\left(S_{\min }<S<S_{\max }\right.$ ) favor chondrocytes differentiation and cartilage production. High values of the stimulus $\left(S_{\max }<S\right)$ favor fibroblast differentiation and fibrous tissue production. Therefore, $F_{f}, F_{c}$ and $F_{b}$ are differentiation rates that also depend on $S$ (see Appendix 4). Evolution of chondrocytes and osteoblast cell densities is modelled in a similar way, but it is assumed that they do not migrate:

$$
\begin{aligned}
\frac{\mathrm{d} c_{c}}{\mathrm{~d} t}= & P_{c}\left(1-c_{\mathrm{tot}}\right) c_{c}+F_{c}\left(1-c_{c}\right)\left(c_{m}+c_{f}\right) \\
& -F_{b}\left(1-c_{b}\right) c_{c}, \\
\frac{\mathrm{d} c_{b}}{\mathrm{~d} t}= & P_{b}\left(1-c_{\mathrm{tot}}\right) c_{b}+F_{b}\left(1-c_{b}\right)\left(c_{m}+c_{f}+c_{c}\right) .
\end{aligned}
$$

Here $P_{c}$ and $P_{b}$ are chondrocyte and osteoblast proliferation rates that also depend on cartilage and bone volume fractions and on the mechanical stimulus $S$. Tissues production and replacement is regulated by the corresponding cells, tissues themselves and mechanical stimulation:

$$
\begin{aligned}
\frac{\mathrm{d} m_{b}}{\mathrm{~d} t} & =Q_{b}\left(1-m_{b}\right) c_{b}, \\
\frac{\mathrm{d} m_{c}}{\mathrm{~d} t} & =Q_{c}\left(1-m_{b}-m_{c}\right) c_{c}-D_{b} c_{b} m_{c} m_{\mathrm{tot}}, \\
\frac{\mathrm{d} m_{f}}{\mathrm{~d} t} & =Q_{f}\left(1-m_{t o t}\right) c_{f}-\left(D_{b} c_{b}+D_{c} c_{c}\right) m_{f} m_{\mathrm{tot}} .
\end{aligned}
$$

Here $m_{b}, m_{c}$ and $m_{f}$ are bone, cartilage and fibrous tissue volume fractions, respectively, $Q_{b}, Q_{c}$ and $Q_{f}$ are production rates of the corresponding tissues. The production rates are also functions of $S$ (see Appendix 4). $D_{b}$ and $D_{c}$ are tissue resorption rates that are chosen to be equal to $Q_{b}$ and $Q_{c} . m_{\mathrm{tot}}=m_{f}+m_{c}+m_{b}$ is the volume fraction of all tissues except the granulation tissue, which volume fraction is $1-m_{\text {tot }}$. The system of equations (1)-(7) has this property that as soon as equality $m_{\text {tot }}=m_{f}+m_{c}+m_{b}=1$ (no granulation tissue) is achieved, it will hold permanently.

The mechanical component of the model is meant for the calculation of the stimulus $S$ in the callus. All tissues in the callus were modelled as poroelastic, using a finite strain formulation and Neo-Hookean hyperelastic properties for the solid phase. Cortical bone was modelled as linear elastic. The material properties of the tissues are presented in Table 1 . Stiffness of the granulation tissue was calculated similar to Lacroix and Prendergast (2002a), by fitting Young's modulus of the granulation tissue in such a way that $500 \mathrm{~N}$ force applied to the cortex results in approximately $1 \mathrm{~mm}$ of interfragmentary motion. This is also consistent with the experiment of Claes et al. (1998). The obtained overall stiffness was $188 \mathrm{kPa}$. Since several tissues can coexist together in one material point, mechanical properties at this point are 
Table 1 Material properties

\begin{tabular}{|c|c|c|c|c|c|}
\hline Material & $\begin{array}{l}\text { Young's } \\
\text { modulus } \\
(\mathrm{MPa})\end{array}$ & $\begin{array}{l}\text { Poisson's } \\
\text { ratio }\end{array}$ & $\begin{array}{l}\text { Permea- } \\
\text { bility } \\
\left(\mathrm{m}^{4} \mathrm{~N}^{-1} \mathrm{~s}^{-1}\right)\end{array}$ & Porosity & $\begin{array}{l}\text { Fluid } \\
\text { bulk } \\
\text { modulus } \\
(\mathrm{MPa})\end{array}$ \\
\hline Cortical bone & $20000^{\mathrm{a}}$ & $0.3^{\mathrm{a}}$ & - & - & - \\
\hline Mature bone & $6000^{\mathrm{a}}$ & $0.3^{\mathrm{a}}$ & $3.7 \times 10^{-13^{b}}$ & 0.8 & $2300^{c}$ \\
\hline Cartilage & $10^{\mathrm{d}}$ & $0.1667^{\mathrm{e}}$ & $5 \times 10^{-15^{f}}$ & 0.8 & $2300^{c}$ \\
\hline Fibrous tissue & $2^{\mathrm{d}}$ & $0.1667^{\mathrm{e}}$ & $1 \times 10^{-14^{g}}$ & 0.8 & $2300^{c}$ \\
\hline Gran. tissue & 0.188 & $0.1667^{\mathrm{e}}$ & $1 \times 10^{-14 \mathrm{~g}}$ & 0.8 & $2300^{c}$ \\
\hline
\end{tabular}

a - Claes and Heigele (1999)

b - Ochoa and Hillberry (1992)

c - Anderson CB (1967)

d - Hori and Lewis (1982)

e - Spilker et al. (1988)

f - Armstrong and Mow (1982)

g - Estimated by Prendergast et al. (1997) based on Armstrong and Mow (1982) and Levick (1987)

calculated by the rule of mixtures (Lacroix and Prendergast 2002a):

$$
\text { Total property }=\sum_{i} \text { single tissue property }_{i} \times m_{i} \text {. }
$$

The set of partial differential equations (1)-(7) was solved using a finite element model (Appendix 4), which was formulated using the Galerkin method. Semi-implicit time integration procedure was used. The resulting nonlinear system was solved by a Newton iterative scheme. The formulation was implemented as a four-node tetrahedral user element in MSC Marc (version 2003r2, Palo Alto, USA) and successfully validated using a one-dimensional Matlab solution. A finite strain poroelastic four-node tetrahedral user element was also implemented in MSC Marc (Andreykiv A 2006). All simulations were performed on a 8-node parallel network cluster.

\subsection{Calibration of the model}

Calibration of the model was performed using animal test results, reported by Claes et al. (1995) and Claes and Heigele (1999). In these studies the authors investigated the influence of the osteotomy gap size on the fracture healing process. Several groups of sheep underwent a standardized transverse osteotomy of the right metatarsal. The osteotomy was stabilized by a specially designed external ring fixator with extremely high bending and torsional stiffness, while allowing axial movements through a telescoping system. Weight bearing in the operated limb produced an axial telescoping, corresponding to a controlled interfragmentary movement. The change of interfragmentary movement was monitored weekly.

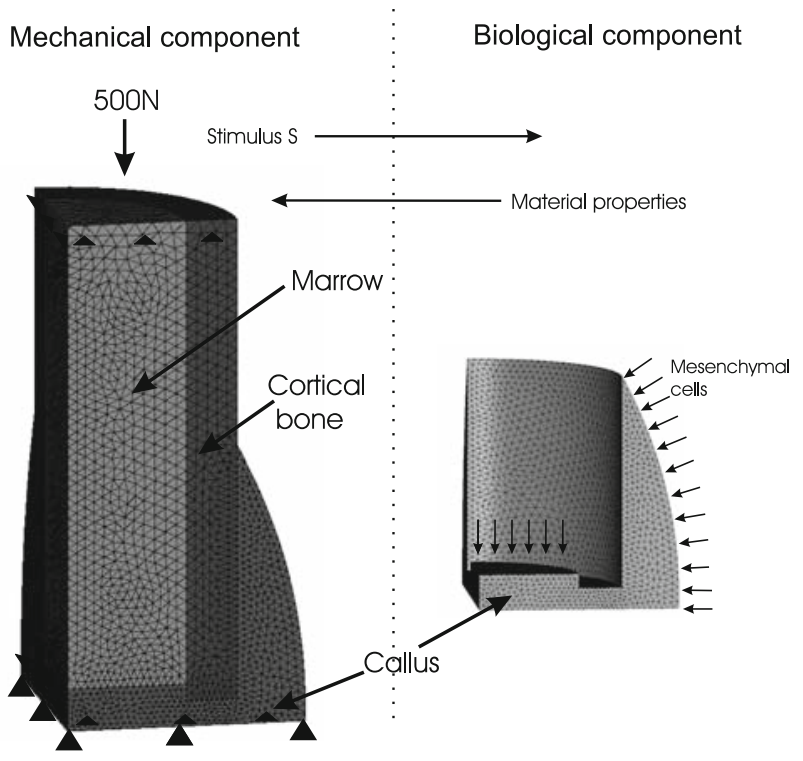

Fig. 2 Finite Element mesh, used for the calibration of the model

The proposed model was calibrated to the results of the group of sheep with $3 \mathrm{~mm}$ gap size and approximately $1 \mathrm{~mm}$ initial interfragmentary movement. The calibrated values were cell differentiation rates $\left(F_{b_{\min }}, F_{b_{\max }}, F_{c_{\max }}, F_{f_{\max }}\right)$, tissue production rates $\left(Q_{b_{\min }}, Q_{b_{\max }}, Q_{c_{\max }}, Q_{f_{\max }}\right.$, see Appendix 4 for the definitions), time period for mesenchymal cells boundary condition application and, as was mentioned before, initial callus stiffness. The goal of the calibration was to obtain realistic kinetics of interfragmentary movement and tissue distribution, i.e. similar to the ones, reported by Claes et al. (1995) and Claes and Heigele (1999).

A 3D finite element mesh, used for the calibration, was build from the axisymmetric geometry introduced by Lacroix and Prendergast (2002a). Due to axial symmetry, the geometry 
was simplified to one eighth of the cortical bone with marrow and callus (Fig. 2). The mechanical component of the model simulates the mechanical environment, as described by Claes and Heigele (1999). The bottom nodes of the mesh are constrained in vertical direction and a vertical axial force of $500 \mathrm{~N}$ is applied in $0.5 \mathrm{~s}$ (the force is linearly dependent on time). Symmetry boundary conditions are applied to the sides of the model. Exchange of fluid between the callus and the marrow is allowed (they share common nodes) while fluid flux on the surface of the joint marrow/callus geometry is set to zero. The biological component of the model was modelled only in the callus region of the mesh, where the healing takes place. As was mentioned before, saturated mesenchymal cell density was prescribed at the periosteum layer and bone marrow interface and kept constant for a short period of time, the latter is determined from the calibration of the model.

Initially, all cell densities are zero, except those prescribed as boundary conditions. First, the biological model starts. It immediately invokes a mechanical simulation which runs with the initial material properties of the callus. When the mechanical simulation is finished, it passes the calculated stimulus $S$ to the biological part. The biological part simulates one day of the healing process and invokes the mechanical simulation with new callus material properties. This cycle is repeated until 7 weeks of the healing process is simulated.

\subsection{Corroboration of the model}

The model was corroborated against the ovine experiment reported by Goodship et al. (1998). The latter investigated the effect of strain rate and timing of mechanical stimulation on fracture healing. In this experiment a middiaphyseal osteotomy was created to form a 3-mm gap which is stabilized with a unilateral external fixator. The fixator was applied to the cranial aspect of the tibia. The sheep walked within $24 \mathrm{~h}$ of surgery and the fixator frames were left in situ for 12 weeks. In the first part of the study three groups of skeletally mature female sheep were used in which displacement rates of 2, 40, and $400 \mathrm{~mm}$ per second were applied using a microprocessor controlled actuator. An initial displacement was used, applied with a force of $200 \mathrm{~N}$ at $0.5 \mathrm{~Hz}$ for 5 consecutive days per week for 12 weeks. The second part of the study used an additional group of six sheep. The osteotomies in this group were subjected to the same stimulation (400 $\mathrm{mm} \mathrm{s}^{-1}$ of applied cyclic micromovement) as the preceding groups, but the stimulation was initiated at 6 weeks postoperatively when periosteal bridging had commenced.

In order to simulate the described experiment, some adjustments to the calibrated model were needed. In order to take into account the bending moment, caused by walking, one fourth of the fractured bone had to be simulated (Fig. 3).

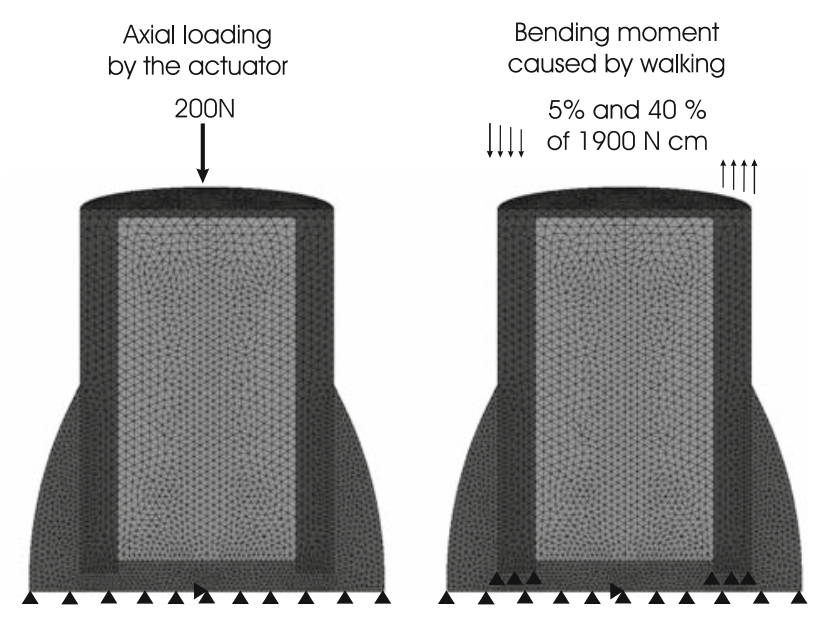

Fig. 3 Finite Element mesh and boundary conditions used for the corroboration of the model. Both, axial and bending loads were applied to the top nodes of the cortex mesh

The simulation aims at replicating the loading conditions, reported by Goodship et al. (1998). Hence both axial loading, applied by the microprocessor controlled actuator, and bending loading, applied when the sheep was walking with the locked fixator, are simulated. Due to the fact that in the animal experiment the axial stimulation was applied separate from the bending stimulation, separate purely axial and purely bending simulations are performed. The magnitude of $S$, that is passed to the tissue-differentiation model every day, is taken as a maximum of the two values, calculated from the two loading regimes. Similarly to the animal experiment, the axial stimulation is simulated only during the working days (Monday till Friday), while the bending moment is applied during every day of the simulated period, since in the animal experiment the sheep were allowed to walk freely. Duda et al. (1998) showed that the maximum bending moment during the sheep's gait is $1900 \mathrm{~N} \mathrm{~cm}$. Similarly to Bailon-Plaza and van der Meulen 2003, we investigate the influence of the bending moment by using $5 \%$ and then $40 \%$ of this value. The corresponding moment is applied to the bone as a linearly distributed pressure. In the experiment by Goodship et al. (1998), an initial displacement of $1 \mathrm{~mm}$ was caused by application of $200 \mathrm{~N}$ force. In order to replicate this behavior, the initial callus stiffness is changed to $0.085 \mathrm{MPa}$, which was the result of the calibration.

In order to study the influence of the loading frequency, as reported in the animal experiment, two displacement rates of 2 and $40 \mathrm{~mm} \mathrm{~s}^{-1}$ are simulated. As in the experiment, the above rates are applied by $200 \mathrm{~N}$ axial load in 0.5 and $0.025 \mathrm{~s}$, respectively.

In total, four corroboration numerical experiments are performed. First, the one with $2 \mathrm{~mm} \mathrm{~s}^{-1}$ displacement rate for the axial loading and $5 \%$ of the total bending moment. Second, the one with $2 \mathrm{~mm} \mathrm{~s}^{-1}$ displacement rate for the axial loading and $40 \%$ of the total bending moment. Third, 
the one with $40 \mathrm{~mm} \mathrm{~s}^{-1}$ displacement rate and $5 \%$ of the total bending moment. Forth, the one with $40 \mathrm{~mm} \mathrm{~s}^{-1}$ displacement rate and $40 \%$ of total bending moment.

The results of the simulations are presented as spatial distribution of cells and tissue densities in the callus at different time points. Interfragmentary movement, axial stiffness and bone fractions were also calculated. Axial stiffness was calculated similar to Bailon-Plaza and van der Meulen 2003, by applying $100 \mathrm{~N}$ load and dividing this load by the average nodal displacement of the cortex at the osteotomy gap. Average bone fraction was calculated in the whole callus and at the osteotomy plane. Axial stiffness and bone fraction results were qualitatively compared to the walking stiffness index and the bone mineral content at the osteotomy line, measured by Goodship et al. (1998).

\subsection{Parameter study}

After the calibration study established the base magnitudes of the model parameters, sensitivity of the model to minor variation of these parameters was studied. Only the model, that was used for the calibration was used for the parameter study. Each of the 18 parameters was increased by $10 \%$ of its base value and the same simulation, that was used for the calibration of the model, was performed. Hence 18 simulations were performed to show the sensitivity to variation of each individual parameter. The results of the parameter study are demonstrated by the influence of each parameter variation on the interfragmentary movent, average bone, cartilage and fibrous tissue fractions in the callus.

\section{Results}

Calibration of the model produced the following values for the model parameters: cell differentiation rates $F_{b_{\min }}=$ 0.005 day $^{-1}, F_{b_{\max }}=0.15 \mathrm{day}^{-1}, F_{c_{\max }}=0.3 \mathrm{day}^{-1}, F_{f_{\max }}=$ 0.01 day $^{-1}$, tissue production rates $Q_{b_{\min }}=0$ day $^{-1}$, $Q_{b_{\max }}=0.1$ day $^{-1}, Q_{c_{\max }}=0.2$ day $^{-1}, Q_{f_{\max }}=0.06$ day $^{-1}$, time period for maintaining the mesenchymal cells boundary conditions at the periosteum layer-one week. Using these parameters the model could successfully reproduce the interfragmentary movement history obtained by Claes et al. (1995) and Claes and Heigele (1999) (Fig. 4). Tissue differentiation inside the callus also compares well with the scheme reported by Claes and Heigele (1999). Initially, the callus is filled with granulation tissue only. The following event is invasion of the mesenchymal cells and their subsequent differentiation into osteoblasts along the bone sides (Fig. 5), and fibroblast and chondrocyte differentiation in the gap area. The corresponding tissue production has a similar pattern to the cell density distribution (Fig. 6). Similarly to the animal experiment of Claes et al. (1995), the model did

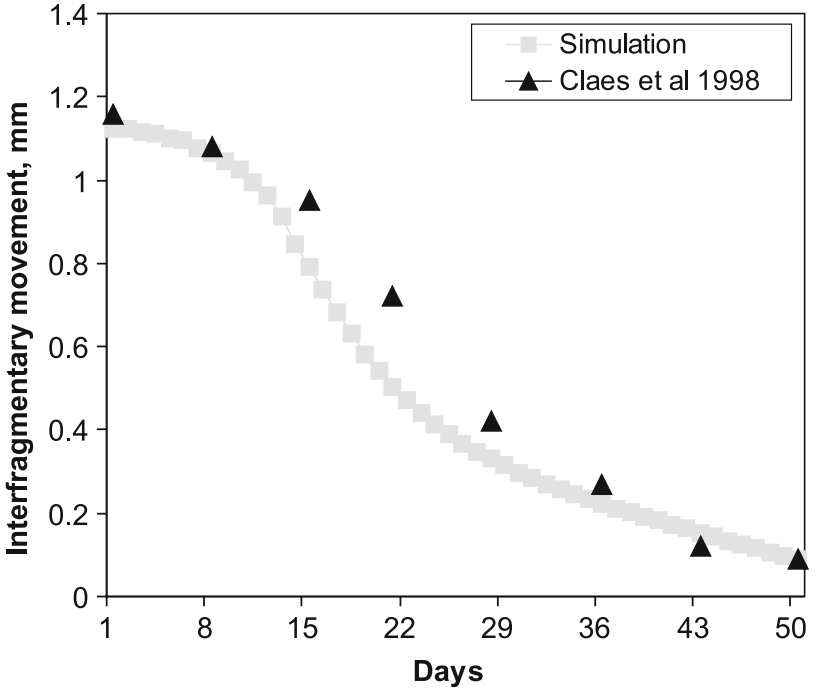

Fig. 4 Simulated and experimentally observed interfragmentary movement

not predict bone bridging of the osteotomy gap, leaving some space filled with cartilage tissue. The cell differentiation is governed by the biophysical stimulus $S$, which reduces gradually, as the callus gets stiffer (Fig. 7).

The results of the parameter study show that the model is relatively insensitive to small variations of each individual parameter (Fig. 8). The only parameter whose variation caused a visible deviation of average bone fractions and interfragmentary movement from the result of the unperturbed model was $S_{\max }$. But even for this specific parameter the general behaviour of the model did not change and the tissue patterns were very similar to the ones produced by the unperturbed model.

Application of a small bending moment (5\% of the $1,900 \mathrm{Nm}$ maximum value) in the first corroboration simulation ( $2 \mathrm{~mm} \mathrm{~s}^{-1}$ displacement rate) does not substantially change the tissue distribution pattern (Fig. 9) as compared to the pattern in the calibration simulation with pure uniaxial loading (Fig. 6). Application of the higher bending moment (40\% of the $1900 \mathrm{Nm}$ maximum value) disturbs the symmetry of the tissue distribution (Fig. 10). The bending moment causes some extra stimulation of the external callus (Fig. 11, right) which leads to the additional bone and cartilage production in this area. This additional stimulation also causes increase of the average bone density in the whole callus (Fig. 15a) and in the osteotomy plane (Fig. 15b). The increase of the bone density in the osteotomy plane results in the increase of the axial stiffness (Fig. 16a) and subsequent decrease in the interfragmentary movement (Fig. 16b).

Higher displacement rate also changes the tissue distribution pattern in the callus (Figs. 12 and 13). It increases the stimulus $S$ (Fig. 14), which causes more cartilage and bone formation in certain areas of the callus (Fig. 15a). However, the tissue distribution, caused by the higher displacement 
Fig. 5 Cell concentrations inside the callus for the calibration simulation
Fig. 6 Tissue fractions inside the callus for the calibration simulation
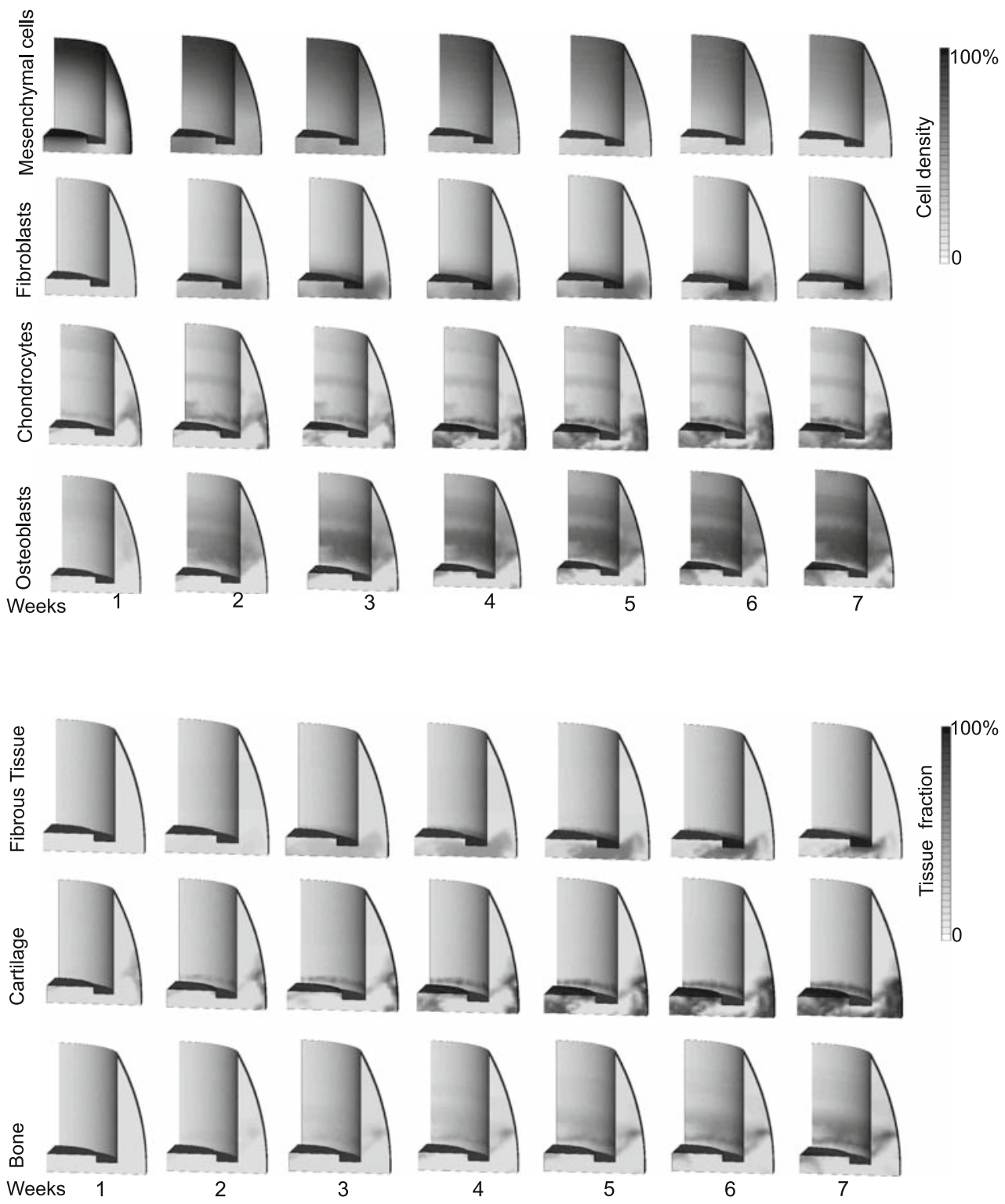

Fig. 7 Biophysical stimulus $S$ for the calibration simulation

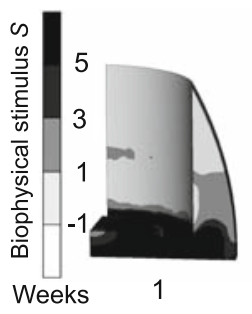

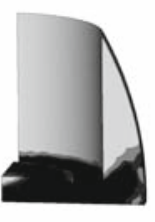

2

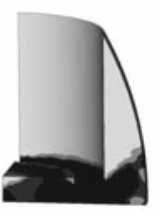

3

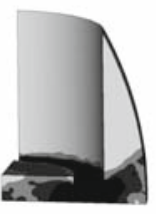

4

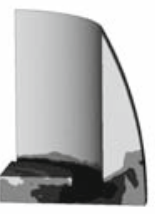

5

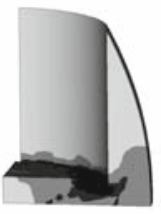

6

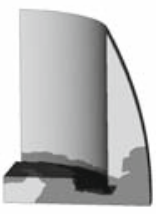

7 rate, is such that the ossification front propagation is delayed. As a result, the axial stiffness (Fig. 16a) and the bone fraction in the osteotomy plane (Fig. 15b) are lower than in case of $2 \mathrm{~mm} / \mathrm{sec}$ displacement rate. Interestingly, at this high displacement rate the model is substantially less sensitive to the variation of the bending moment magnitude, as the distribution of tissues and the biophysical stimulus is quite similar. 
Sensitivity study. Model results with parameters increased by $10 \%$.
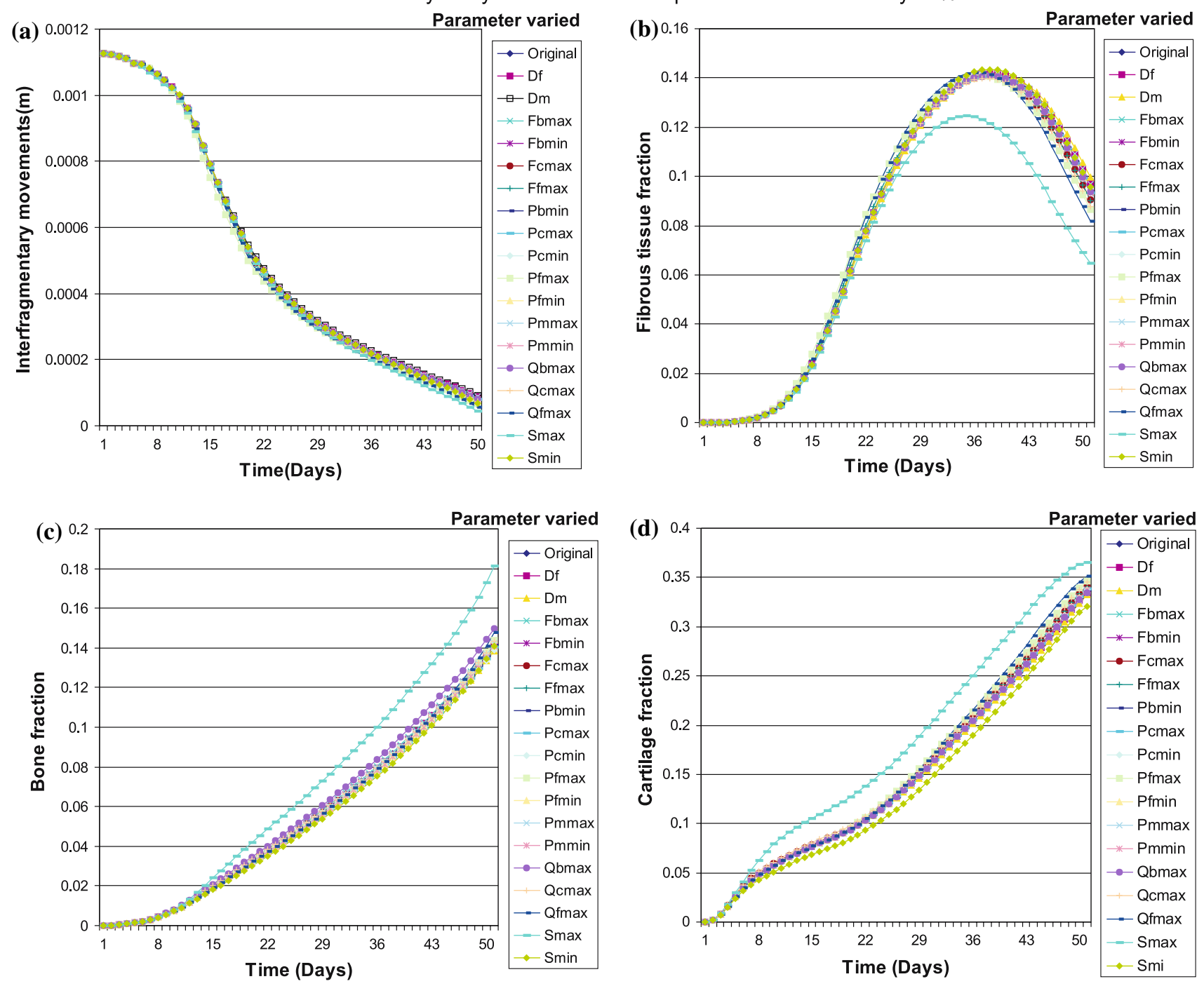

Fig. 8 Sensitivity of the model. Interfragmentary movement (a), fibrous tissue (b), cartilage (c) and bone fractions (d) calculated with the original and the $10 \%$ increased parameters are plotted

\section{Discussion}

In this study we were aiming at the development of a tissue differentiation model for fracture healing that is not only capable of capturing the influence of the mechanical environment on the number of cellular and tissue processes, but can also be implemented in complicated 3D geometries and loading conditions.

In order to model tissue differentiation, some assumptions were necessary. First of all, most of the model parameters were either calibrated in such a way that the results agree with experiments by Claes et al. (1995) or taken from in vitro studies. Clearly, most parameters might vary from species to species or even among individuals. However, the magnitude and the influence of these variations can be roughly estimated. For instance, osteoblast proliferation rates used in the present model were based on four independent in vitro studies, chondrocyte and fibroblast proliferation on two in vitro studies. The parameter study, performed in this work, showed that the model is relatively insensitive to minor variations of the parameter in the vicinity of the base magnitudes, established in the calibration study. In addition, using the same values for $S_{\min }$ and $S_{\max }$, Geris et al. (2004) successfully predicted tissue differentiation inside a bone chamber. The second assumption of the model is a an axisymmetric geometry of the bone and the callus. Apparently, using a real geometry, as it was done by Lacroix and Prendergast (2002b), would contribute to the accuracy of the simulation. However, in this study we wished to demonstrate the predictive abilities of the model in three dimensions and this can now be extended to anatomical geometries without undue difficulty. One more factor that was not explicitly modelled 
Fig. 9 Tissue fractions inside the callus for the simulation with $2 \mathrm{~mm} \mathrm{~s}^{-1}$ displacement rate and $5 \%$ bending moment. The tissue distributions are shown in two perpendicular planes: parallel and perpendicular to the bending direction

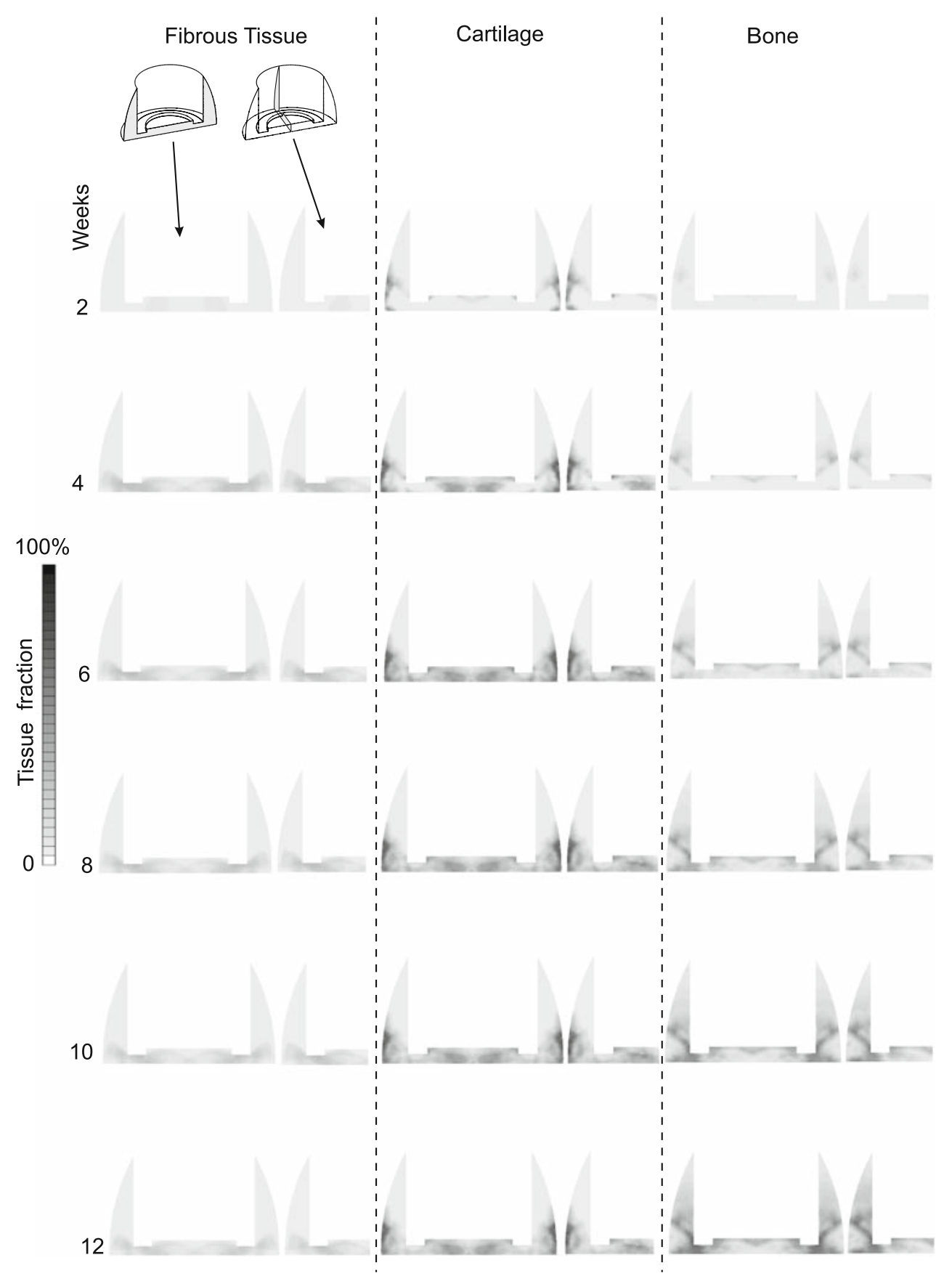

is the stimuli created by growth factors, as it was done by Bailon-Plaza and Van der Meulen (2001) and Bailon-Plaza and van der Meulen 2003. Although significance of the growth factors is an established fact, it remains unclear how important it is to model the growth factors themselves. A number of bone fracture healing models, mentioned earlier in this article, are shown to be capable to predict the main stages of the healing process. Therefore, we hypothesize that the explicit modelling of the growth factors becomes crucial only if the distribution of the growth factors is abnormal. The latter can happen, for instance, in case of absence or altered expression of a single growth factor, which may lead to dramatic fracture healing abberations (King et al. 1994; Kocher and Shapiro 1998). Another example is when the growth factors are administered exogenously to a fracture in order to induce bone formation and accelerated healing (Joyce et al. 1990). Another simplification of the model is simulation of only one loading cycle per day (one axial loading cycle during 5 days per week and one bending loading cycle every day). This way we ignore the accumulative effect of the repetitive cyclic loading. However, in their study on bone adaptation Rubin and Lanyon 1984 demonstrated that 
Fig. 10 Tissue fractions inside the callus for the simulation with $2 \mathrm{~mm} \mathrm{~s}^{-1}$ displacement rate and $40 \%$ bending moment. The tissue distributions are shown in two perpendicular planes: parallel and perpendicular to the bending direction

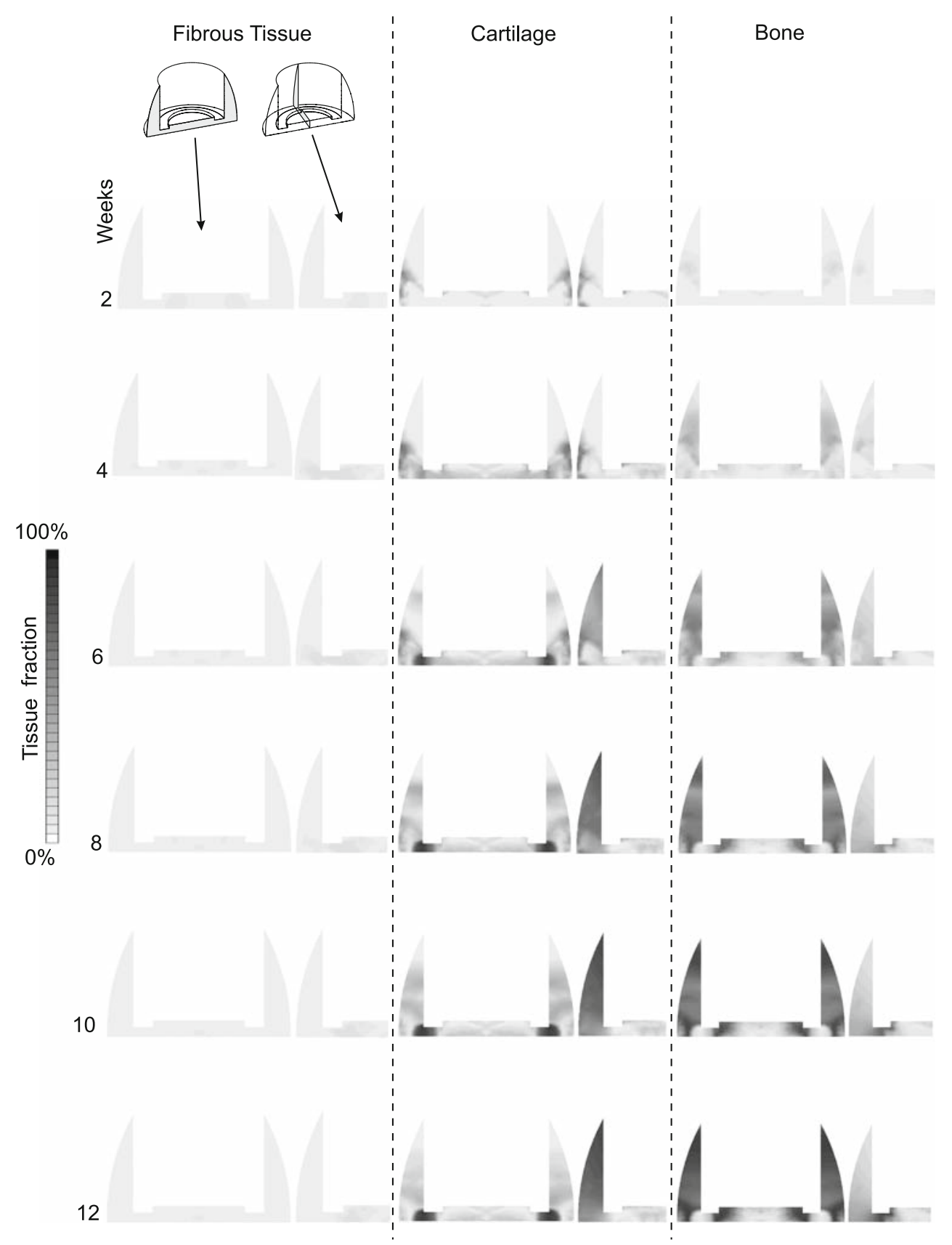

after a certain number of loading cycles per day there is a sort of load saturation, when after some critical number cycles bone does not respond to additional loading cycles anymore. In our study we hypothesize that the same load saturation effect might take place in case of bone fracture healing, and the loading cycle that we simulate every day is an average "characteristic" load from the saturated load regime. Additionally, we used a diffusion equation without taxis terms to model migration of mesenchymal and fibroblast cells. There are only few numerical schemes capable of solving partial differential equations with taxis terms, like the ones, proposed by Gerisch (2001) and Gerisch and Chaplain (2005).
Bailon-Plaza and van der Meulen (2001) were using alternating direction finite difference methods to cope with the taxis terms. The required condition for application of the above methods is the usage of structured discretization grids. One of the goals of this work was an implementation of tissue differentiation model in finite element method that allows unstructured grids. Therefore we decided to build a model that would only be as complete as finite element implementation would allow, hence dropping the taxis terms.

Despite the above limitations, the model was able to predict the tissue differentiation patterns as observed by Claes et al. (1995) and Claes and Heigele (1999). In particular, the 
Fig. 11 Biophysical stimulus $S$ for the simulation with $2 \mathrm{~mm} \mathrm{~s}^{-1}$ displacement rate. The biophysical stimulus distributions are shown in two perpendicular planes: parallel and perpendicular to the bending direction

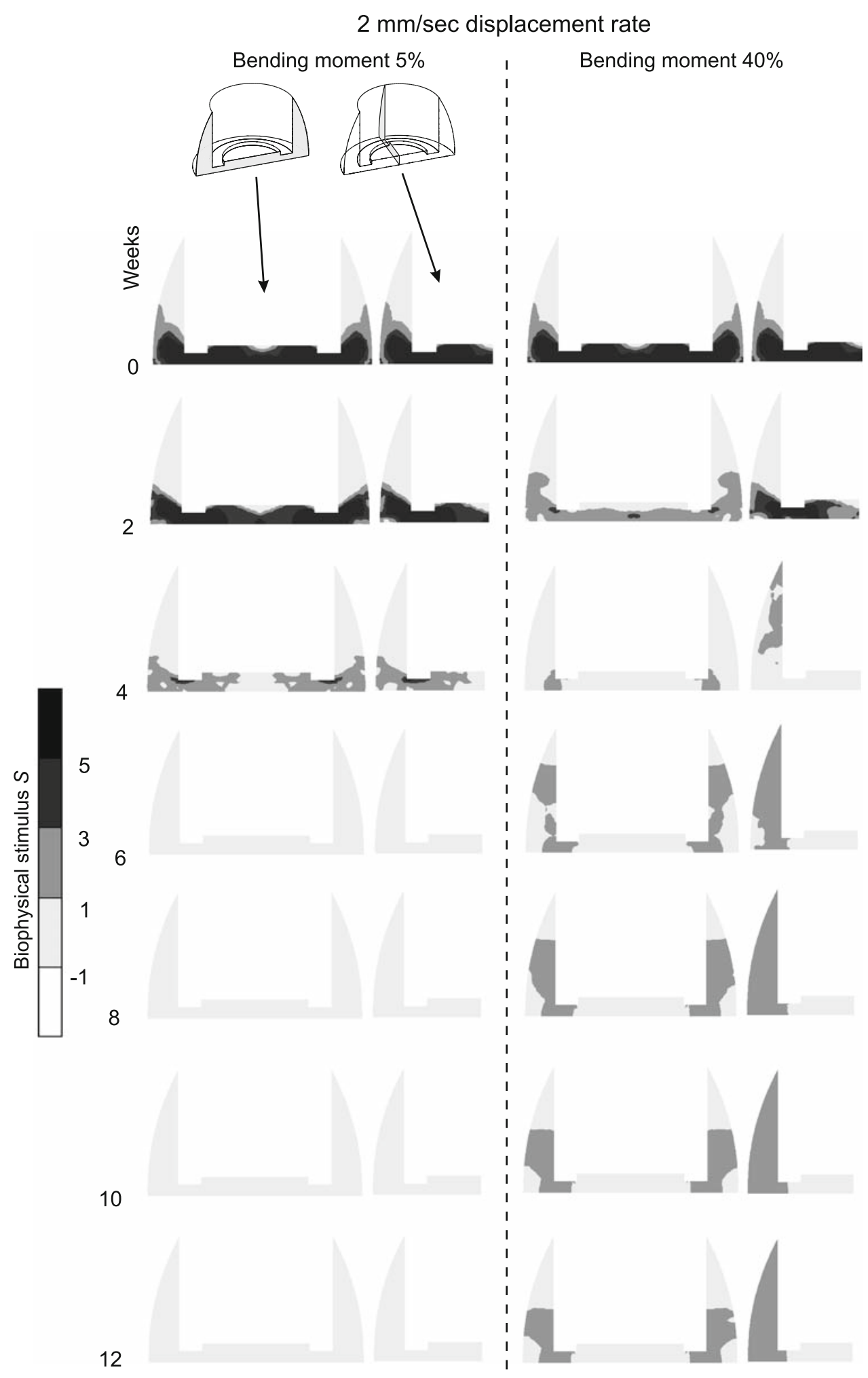

ossification front starts from the external side of the cortical bone and propagates in the direction of the osteotomy plane as the tissue differentiation continued (Fig. 6). Similarly to the animal experiment of Claes et al. (1995), the model did not predict bone bridging of the osteotomy gap, leaving some space filled with cartilage tissue.

However, unlike the experiment of Goodship et al. (1998), the model showed a negative effect of the displacement rate 
Fig. 12 Tissue fractions inside the callus for the simulation with $40 \mathrm{~mm} \mathrm{~s}^{-1}$ displacement rate and $5 \%$ bending moment. The tissue distributions are shown in two perpendicular planes: parallel and perpendicular to the bending direction

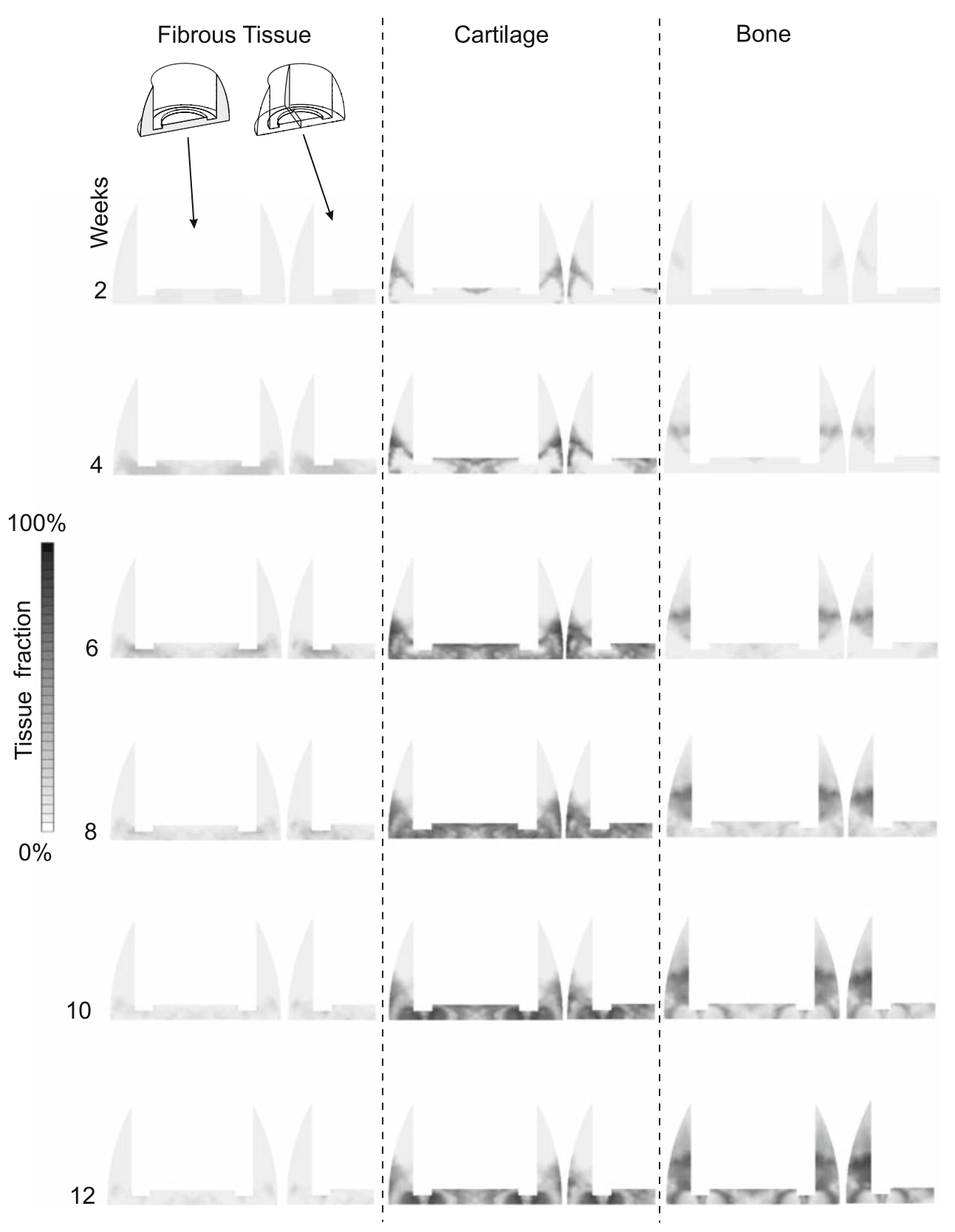

increase on the axial stiffness. Goodship et al. (1998) also observed an increase in the bone mineral content in the osteotomy plane when the applied displacement rate was changed from 2 to $40 \mathrm{~mm} \mathrm{~s}^{-1}$. However, the simulation predicted quite an opposite effect-as the displacement rate is increased from the 2 to $40 \mathrm{~mm} \mathrm{~s}^{-1}$, an average bone fraction in the osteotomy plane decreases (Fig. 15b). However, Goodship's experiment also presents a case of a negative correlation between the applied displacement rate and the bone mineral content in the osteotomy gap: application of $400 \mathrm{~mm} \mathrm{~s}^{-1}$ displacement rate produced lower bone mineral content at the osteotomy gap than $40 \mathrm{~mm} \mathrm{~s}^{-1}$ rate. This might indicate that there is some optimal displacement rate which produces the maximum bone mineral content in the osteotomy gap, but our model is not calibrated efficiently to detect such an optimum, as we did not have enough experiment data to calibrate the model with respect to different loading frequencies (we could not use Goodship's results, as we already used them for corroboration of the model, hence using them also for the calibration would not be appropriate). It is also worth mentioning that, as compared to the result of $2 \mathrm{~mm} \mathrm{~s}^{-1}$ displacement rate, the effect of $40 \mathrm{~mm} \mathrm{~s}^{-1}$ rate was positive for the average bone fraction in the whole callus (Fig. 15a). This is also consistent with Goodship et al. (1998). Radiographs of the callus distribution, presented in Goodship et al. (1998), show higher mineral content in the callus, stimulated 
Fig. 13 Tissue fractions inside the callus for the simulation with $40 \mathrm{~mm} \mathrm{~s}^{-1}$ displacement rate and $40 \%$ bending moment. The tissue distributions are shown in two perpendicular planes: parallel and perpendicular to the bending direction

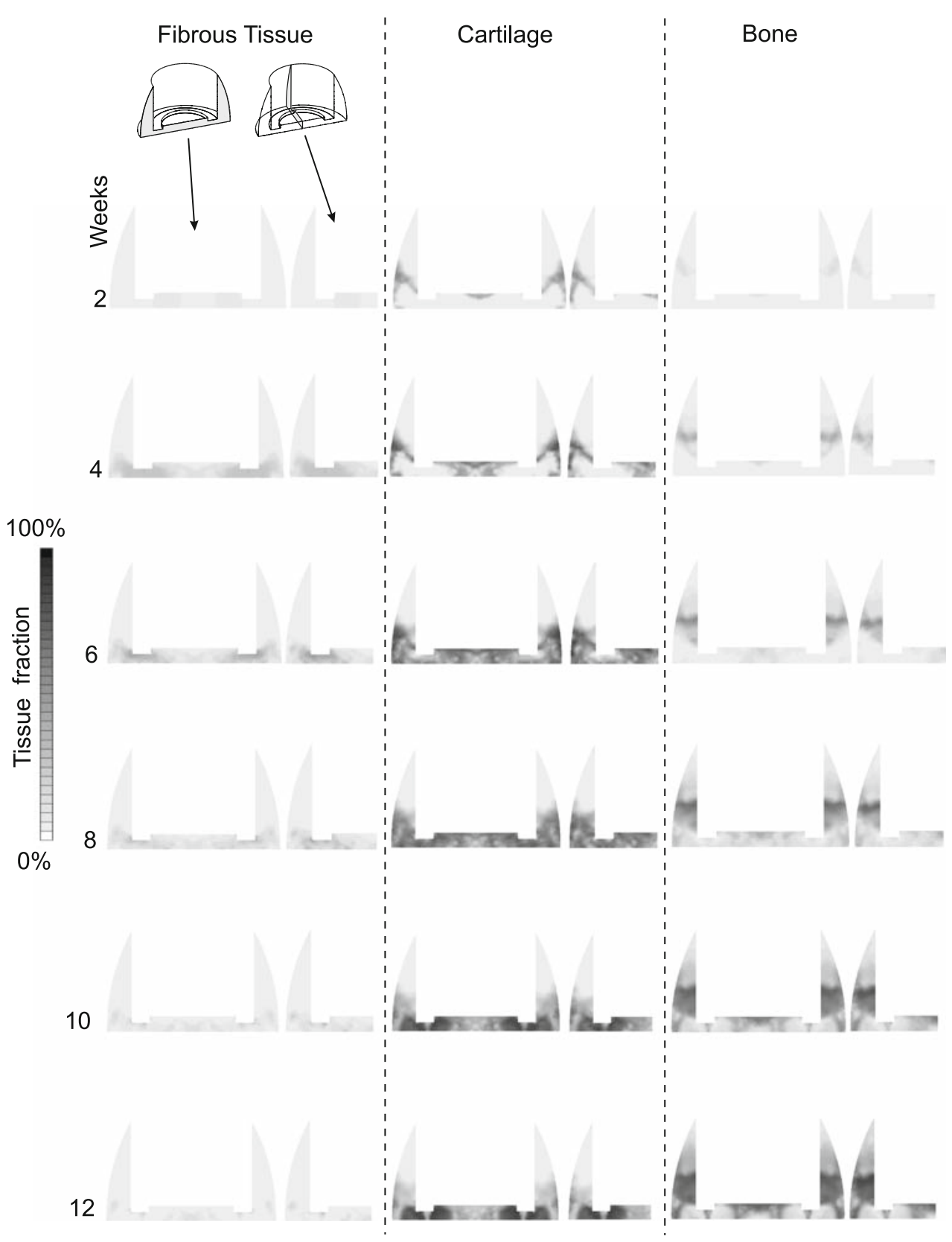

with $40 \mathrm{~mm} \mathrm{~s}^{-1}$ displacement rate, as compared to the one, stimulated with $2 \mathrm{~mm} \mathrm{~s}^{-1}$ displacement rate. Comparison of Goodship's radiographs for the callus, stimulated with 2 and $400 \mathrm{~mm} \mathrm{~s}^{-1}$ displacement rates, might explain why the axial stiffness in the numerical simulation did not show positive correlation with the displacement rate. From the radiographs it looks like the size of the callus stimulated with a $400 \mathrm{~mm} \mathrm{~s}^{-1}$ displacement rate is noticeably larger than the one, stimulated with a $2 \mathrm{~mm} \mathrm{~s}^{-1}$ displacement rate. Apparently the larger size of the callus gives the whole structure higher stiffness. Garcia-Aznar et al. (2007) have made an attempt to simulate callus size growth caused by the cell proliferation.
Based on the results of the simulation we suggest that this model is a step forward as compared to the studies of Lacroix and Prendergast (2002a), Lacroix et al. (2002) and Lacroix and Prendergast (2002b). Unlike the numerical algorithms in these studies, the present model is presented as a set of differential equations where cell proliferation is modelled explicitly, tissues are modelled separate from cells and tissue production rates are not equal for every tissue. Although the model does not allow simulation of the growth factors, like Bailon-Plaza and van der Meulen (2001) and Bailon-Plaza and van der Meulen 2003, it allows for a finite element simulation, which is a definite advantage for complicated geometries and loading conditions. However, the comparison of 
Fig. 14 Biophysical stimulus $S$ for the simulation with $40 \mathrm{~mm} \mathrm{~s}^{-1}$ displacement rate. The biophysical stimulus distributions are shown in two perpendicular planes: parallel and perpendicular to the bending direction

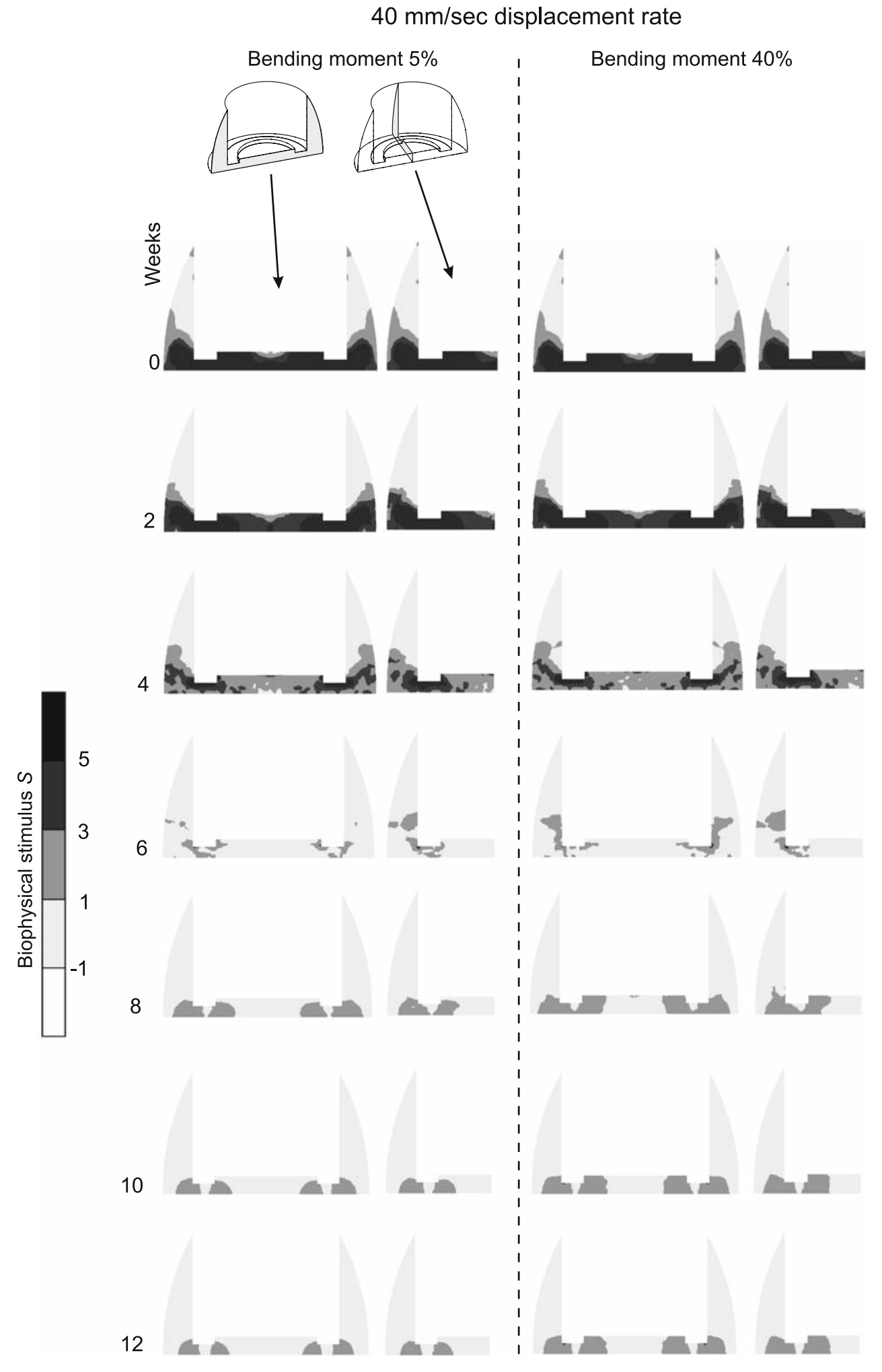

tissue differentiation patterns of our results and results of Bailon-Plaza and van der Meulen 2003 is quite good. Both, the present model (see Fig. 12) and the models presented by Bailon-Plaza and van der Meulen (2001) and Bailon-Plaza and van der Meulen 2003, were able to predict the clinically observed fact (Claes and Heigele 1999) that bone differentiation starts in the external callus near the original cortical bone. However, in Bailon-Plaza and van der Meulen 2003 and 

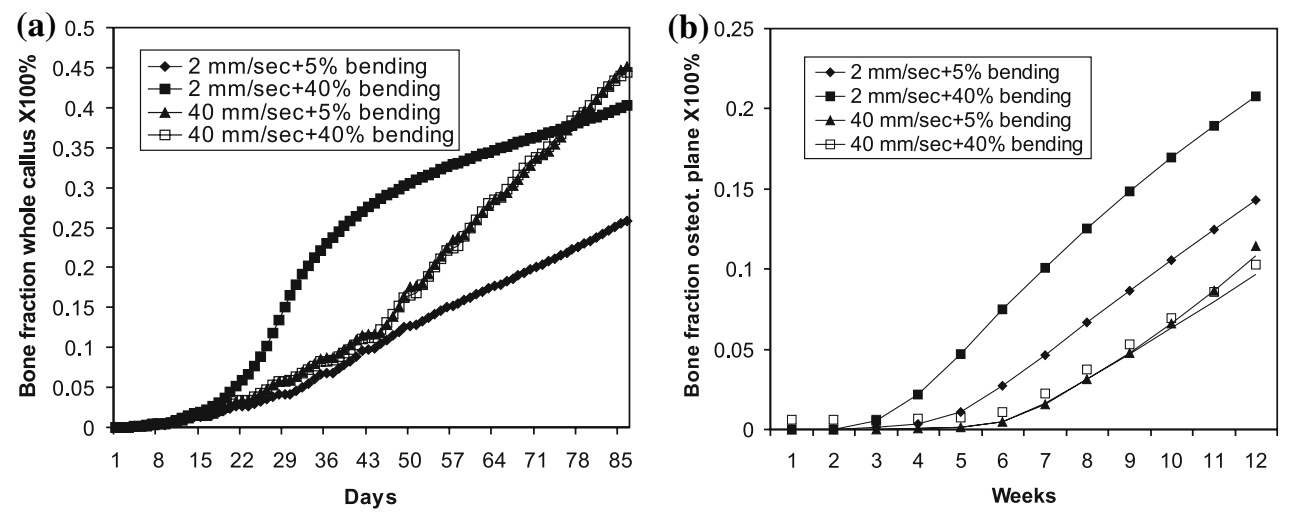

Fig. 15 Average bone fraction in the whole callus (a) and in the osteotomy plane (b) for the corroboration simulations

Fig. 16 Axial stiffness (a) and interfragmentary movement (b) for the corroboration simulations. (The (b) is not continuous because the axial loading was not applied during weekends)
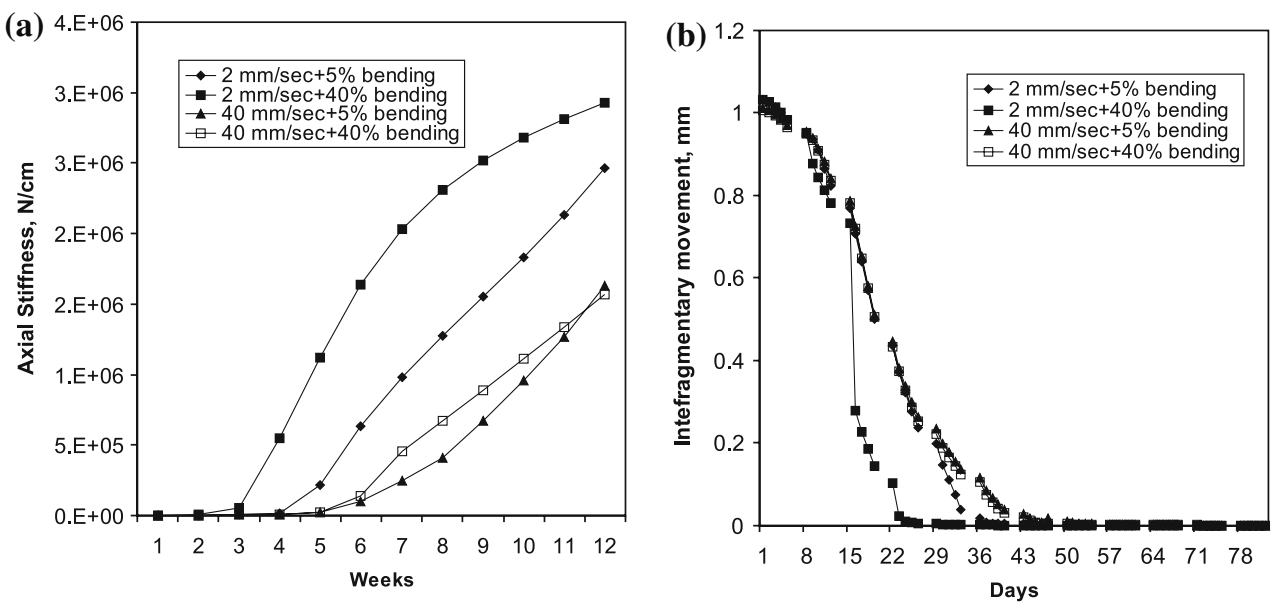

certainly in Bailon-Plaza and van der Meulen (2001) this can be explained by the fact that the bone surface is also a source of the osteoblasts favoring growth factors, while in the presented simulation this comes purely as a result of the mechanical environment. Due to the fact that in Lacroix and Prendergast (2002a), Lacroix et al. (2002) and Lacroix and Prendergast (2002b) the bone is appearing with an equal rate whenever stimulus $S$ is less than unity, the bone differentiation pattern is somewhat different. Although the ability of the model to predict the influence of the loading frequency was proven only partially, this fact makes the model a potential tool in the development of loading protocols used for acceleration of fracture healing processes.

\section{Appendix A: Parameters of the tissue differentiation model}

Estimation of different model parameters was performed based on a number of in vitro studies and mechanoregulation theory of Prendergast et al. (1997).

Diffusion coefficient for mesenchymal cells dispersal was based on leukocyte movement studies (Gruler and
Bültmann (1984)), which gave an estimate for $D_{m_{0}}=240$ $\mu \mathrm{m}^{2} \min ^{-1}=0.3456 \mathrm{~mm}^{2}$ day $^{-1}$. A similar value was obtained by Lacroix et al. (2002) during calibration of their model. Based on Friedl et al. (1998); Bailon-Plaza and van der Meulen (2001) made an estimate of the fibroblasts diffusion coefficient, which resulted in a maximum value of $D_{f_{0}}=60 \mu \mathrm{m}^{2}$ $\min ^{-1}=0.1152 \mathrm{~mm}^{2} \mathrm{day}^{-1}$. The latter was also used in the present model.

A number of authors performed in vitro studies on osteoblast proliferation (Findlay et al. 2004; Lee et al. 2004; Heino et al. 2004; Ushida et al. 2001). Based on these studies, osteoblast proliferation rate $P_{b_{0}}$ can be estimated between 0.5 and $1 \mathrm{day}^{-1}$. In the present study 0.5 day $^{-1}$ was used. Application of a low cyclic strain has a stimulatory effect on the proliferating osteoblasts. From studies of Weyts et al. (2003), Kaspar et al. (2000, 2002), and Kapur et al. (2003) it was estimated that proliferation rate of the stimulated osteoblasts is 1.5 time higher that of non-stimulated ones. Now, assuming that the highest osteoblast proliferation rate will be achieved at the maximum value of the mechanical stimulus $S$, favorable to osteoblasts differentiation, the osteoblast proliferation rate $P_{b_{0}}$ depends on $S$ as depicted in Fig. 17. 
Fig. 17 Cell proliferation rates as functions of stimulus $S$
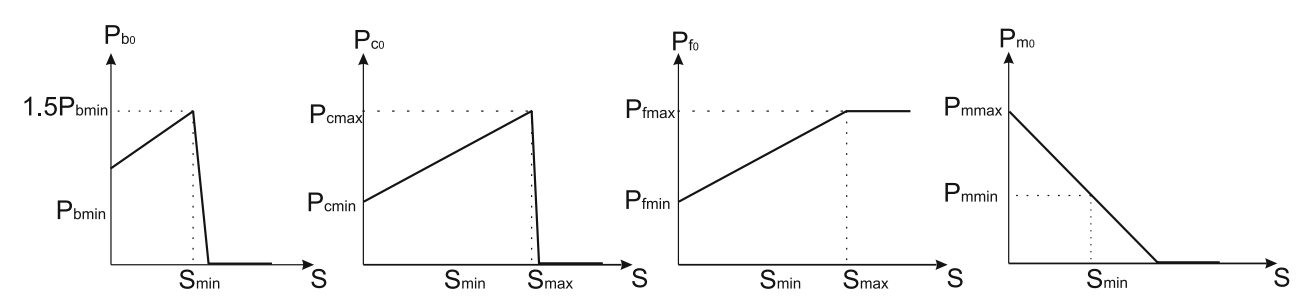

Fig. 18 Cell differentiation rates as functions of stimulus $S$
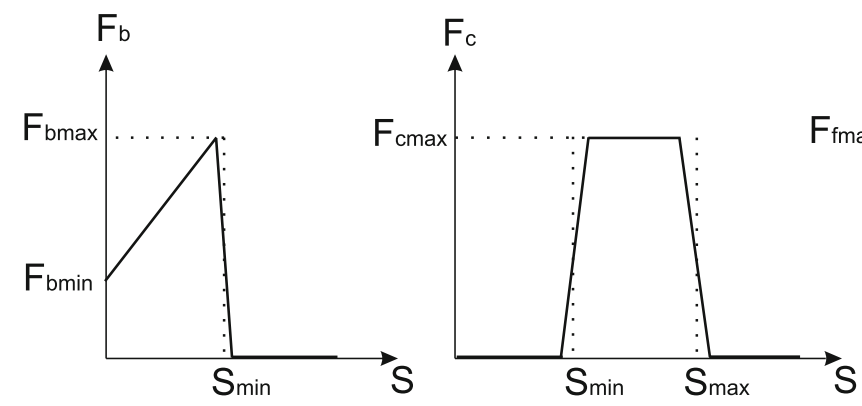

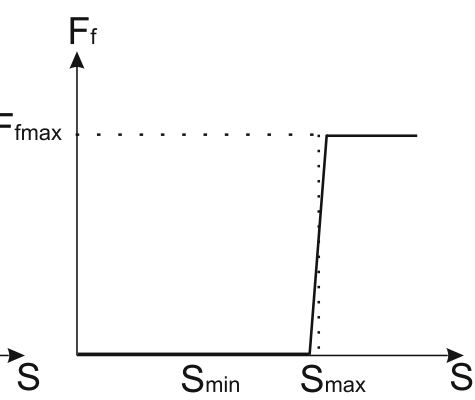

In vitro studies show that non-stimulated chondrocytes proliferate at a rate similar to osteoblasts. Analyzing the results of Zhang et al. (2003) and $\mathrm{Wu}$ and Chen (2000), $P_{c_{0}}$ can be estimated as $0.75 \mathrm{day}^{-1}$, while moderate mechanical stimulation can increase this rate to $0.925 \mathrm{day}^{-1}$. Prendergast et al. (1997) assumed that the most favorable environment for the differentiation and proliferation of chondrocytes is reached when the biophysical stimulus $S$ lies between $S_{\min }$ and $S_{\max }$. Based on this hypothesis and the results of Zhang et al. (2003) in the present chapter it is assumed that $P_{c_{0}}$ depends on $S$ as shown on Fig. 17.

Fibroblasts exhibit much lower proliferation rates without mechanical stimulation. According to Mizuno et al. (2004), proliferation rate of non-stimulated fibroblasts $P_{f_{0}}$ can be estimated as 0.1 day $^{-1}$. The reported stimulated rates (Mizuno et al. 2004; Yang et al. 2004) range between 0.1 and 0.6 day $^{-1}$ ( 0.6 day $^{-1}$ used in this work) and the maximum stimulation is achieved under higher strain levels (Yang et al. 2004). The assumed dependence between $P_{f_{0}}$ and $S$ is shown in Fig. 17.

It remains unclear whether mechanical loading has a positive or a negative effect on proliferation of mesenchymal stem cells. For instance $\mathrm{Ku}$ et al. (2006) and Song et al. (2007) show a positive correlation, while according to Simmons (2003), even small mechanical strain reduces the proliferation rate of mesenchymal cells. For now only the later results are included in this study. According to the study of Simmons (2003), the proliferation rate of the non-stimulated mesenchymal cells $P_{m_{0}}$ can be estimated as 1.2 day $^{-1}$. Mechanical stimulation reduces this rate to around 0.5 day $^{-1}$. Given this data, we assumed the dependence of $P_{m_{0}}$ on $S$ as shown in Fig. 17.

Cell differentiation rates were obtained from calibration of the model presented in this work. The calibrated values
$F_{b_{\min }}, F_{b_{\max }}, F_{c_{\max }}$ and $F_{f_{\max }}$ were used in the dependencies, as shown in Fig. 18. The shape of the rates dependence on stimulus $S$ was assumed taking into account the mechanoregulation model of Prendergast et al. (1997).

Tissue production rates depend on $S$ in the same manner as the differentiation rates, shown in Fig. 18. The corresponding parameters $Q_{b_{\min }}, Q_{b_{\max }}, Q_{c_{\max }}$ and $Q_{f_{\max }}$ were obtained from the calibration of the model.

The lower and the higher thresholds of the stimulus $S$ according to Huiskes et al. (1997) are: $S_{\min }=1, S_{\max }=3$.

\section{Appendix B: Finite element formulation for the tissue differentiation model}

Only Eqs. (1) and (2) have to be solved by the finite element method. The other equations could be solved locally i.e., on element level.

Following the weighted residual method, Eqs. (1) and (2) are multiplied with arbitrary vector functions $\mathbf{w}_{\mathbf{m}}$ and $\mathbf{w}_{\mathbf{f}}$ from $H_{0}^{1}$ (where $H_{0}^{1}$ is a standard Sobolev space, which provides that the function can be integrated along with its first derivatives and vanishes on the boundary) and integrated over the whole domain. Assuming that there are no applied cell fluxes on the boundary (as the later are not used in the simulation), we obtain

$$
\begin{gathered}
\int_{\Omega} \mathbf{w}_{m}^{T}\left[\frac{\mathrm{d} c_{m}}{\mathrm{~d} t}-D_{m} \nabla^{2} c_{m}-P_{m}\left(1-c_{\mathrm{tot}}\right) c_{m}\right. \\
+F_{f}\left(1-c_{f}\right) c_{m}-F_{c}\left(1-c_{c}\right) c_{m} \\
\left.+F_{b}\left(1-c_{b}\right) c_{m}\right] \mathrm{d} \Omega=0
\end{gathered}
$$




$$
\begin{array}{r}
\int_{\Omega} \mathbf{w}_{f}^{T}\left[\frac{\mathrm{d} c_{f}}{\mathrm{~d} t}-D_{f} \nabla^{2} c_{f}-P_{f}\left(1-c_{\mathrm{tot}}\right) c_{f}-F_{f}\left(1-c_{f}\right) c_{m}\right. \\
\left.+F_{c}\left(1-c_{c}\right) c_{f}+F_{b}\left(1-c_{b}\right) c_{f}\right] \mathrm{d} \Omega=0 . \quad(\text { B. } 2)
\end{array}
$$

First we apply Greens theorem to the diffusion terms to eliminate the divergence operator. Furthermore we introduce finite element approximation by dividing the domain into finite elements and approximating the cellular densities $c_{m}$ and $c_{f}$ within the elements by the product of the element nodal values $\mathbf{c}_{\mathbf{m}}$ and $\mathbf{c}_{\mathbf{f}}$ and approximating shape functions $\mathbf{N}$, i.e., $c_{m}=\mathbf{N c}_{\mathbf{m}}$ and $c_{f}=\mathbf{N} \mathbf{c}_{\mathbf{f}}$. By applying Galerkin's method, the weighting functions $\mathbf{w}_{\mathbf{m}}$ and $\mathbf{w}_{\mathbf{f}}$ are replaced by the interpolating shape functions $\mathbf{N}$. The resulting equations on element level are:

$$
\begin{aligned}
\mathbf{C} \frac{\mathrm{d} \mathbf{c}_{\mathbf{m}}}{\mathrm{d} t}+\mathbf{K}_{\mathbf{m}} \mathbf{c}_{\mathbf{m}}-\left[P_{m}\left[1-c_{c}-c_{b}\right]-F_{f}\right. \\
\left.\quad-F_{c}\left[1-c_{c}\right]-F_{b}\left[1-c_{b}\right]\right] \mathbf{C c}_{\mathbf{m}} \\
\quad+\left[P_{m}-F_{f}\right] \mathbf{p}_{\mathbf{m i x}}\left(\mathbf{c}_{\mathbf{m}}, \mathbf{c}_{\mathbf{f}}\right)+P_{m} \mathbf{p}_{\mathbf{n}}\left(\mathbf{c}_{\mathbf{m}}\right)=0, \\
\mathbf{C} \frac{d \mathbf{c}_{\mathbf{f}}}{d t}+\mathbf{K}_{\mathbf{f}} \mathbf{c}_{\mathbf{f}}-\left[P_{f}\left[1-c_{c}-c_{b}\right]\right. \\
\left.-F_{c}\left[1-c_{c}\right]-F_{b}\left[1-c_{b}\right]\right] \mathbf{C c}_{\mathbf{f}} \\
\quad-F_{f} \mathbf{C c}_{\mathbf{m}}+\left[P_{f}+F_{f}\right] \mathbf{p}_{\mathbf{m i x}}\left(\mathbf{c}_{\mathbf{m}}, \mathbf{c}_{\mathbf{f}}\right) \\
\quad+P_{f} \mathbf{p}_{\mathbf{n}}\left(\mathbf{c}_{\mathbf{f}}\right)=0,
\end{aligned}
$$

with

$$
\begin{aligned}
& \mathbf{C}=\int_{V_{e l}} \mathbf{N}^{\mathbf{T}} \mathbf{N} \mathrm{d} V_{\mathrm{el}}, \\
& \mathbf{K}_{\mathbf{i}}=\int_{V_{\mathrm{el}}} \nabla \mathbf{N}^{\mathbf{T}} D_{i} \nabla \mathbf{N} \mathrm{d} V_{\mathrm{el}}, \quad i=m, f, \\
& \mathbf{p}_{\mathbf{n}}=\int_{V_{\mathrm{el}}} \mathbf{N}^{\mathbf{T}}\left(\mathbf{c}_{\mathbf{i}} \mathbf{N}\right)^{2} \mathrm{~d} V_{\mathrm{el}}, \quad i=m, f, \\
& \mathbf{p}_{\mathbf{m i x}}=\int_{V_{\mathrm{el}}} \mathbf{N}^{\mathbf{T}}\left(\mathbf{c}_{\mathbf{m}} \mathbf{N}\right)\left(\mathbf{c}_{\mathbf{f}} \mathbf{N}\right) \mathrm{d} V_{\mathrm{el}} .
\end{aligned}
$$

Next we apply time discretization. First, we replace the time derivatives with the finite differences: $\frac{\mathrm{d} \mathbf{c}_{\mathbf{m}}}{\mathrm{d} t}=\frac{\Delta \mathbf{c}_{\mathbf{m}}}{\Delta t}=$ $\frac{\left(\mathbf{c}_{\mathbf{m}_{\mathbf{n}+\mathbf{1}}}-\mathbf{c}_{\mathbf{m}_{\mathbf{n}}}\right)}{\Delta t}$ and $\frac{\mathrm{d} \mathbf{c}_{\mathbf{f}}}{\mathrm{d} t}=\frac{\Delta \mathbf{c}_{\mathbf{f}}}{\Delta t}=\frac{\left(\mathbf{c}_{\mathbf{n}+\mathbf{1}}-\mathbf{c}_{\mathbf{f}_{\mathbf{n}}}\right)}{\Delta t}$. Then, in each equation of the system, a variable is solved implicitly (taken at the yet unknown time step $n+1$ ) only if that equation represents the rate of that variable. More specifically, in Eq. (B.3) $\mathbf{c}_{\mathbf{m}}$ is replaced with $\mathbf{c}_{\mathbf{m}_{\mathbf{n}+1}}$ and in Eq. (B.4) $\mathbf{c}_{\mathbf{f}}$ is replaced with $\mathbf{c}_{\mathbf{f}_{\mathbf{n}+1}}$. All the other variables are taken with index $n$ (hence, they are known). We obtain:

$$
\begin{aligned}
\mathbf{C} & \frac{\left(\mathbf{c}_{\mathbf{m}_{\mathbf{n}+1}}-\mathbf{c}_{\mathbf{m}_{\mathbf{n}}}\right)}{\Delta t}+\mathbf{K}_{\mathbf{m}} \mathbf{c}_{\mathbf{m}_{\mathbf{n}+\mathbf{1}}} \\
& -\left[P_{m}\left[1-c_{c_{n}}-c_{b_{n}}\right]\right. \\
& \left.-F_{f}-F_{c}\left[1-c_{c_{n}}\right]-F_{b}\left[1-c_{b_{n}}\right]\right] \mathbf{C}_{\mathbf{m}_{\mathbf{n}+\mathbf{1}}} \\
& +\left[P_{m}-F_{f}\right] \mathbf{p}_{\mathbf{m i x}}\left(\mathbf{c}_{\mathbf{m}_{\mathbf{n}+\mathbf{1}}}, \mathbf{c}_{\mathbf{f}_{\mathbf{n}}}\right)+P_{m} \mathbf{p}_{\mathbf{n}}\left(\mathbf{c}_{\mathbf{m}_{\mathbf{n}+\mathbf{1}}}\right)=0, \\
\mathbf{C} & \frac{\left(\mathbf{c}_{\mathbf{f}_{\mathbf{n}+\mathbf{1}}}-\mathbf{c}_{\mathbf{f}_{\mathbf{n}}}\right)}{\Delta t}+\mathbf{K}_{\mathbf{f}} \mathbf{c}_{\mathbf{f}_{\mathbf{n}+\mathbf{1}}} \\
& -\left[P_{f}\left[1-c_{c_{n}}-c_{b_{n}}\right]-F_{c}\left[1-c_{c_{n}}\right]-F_{b}\left[1-c_{b_{n}}\right]\right] \mathbf{C c}_{\mathbf{f}_{\mathbf{n}+\mathbf{1}}} \\
& -F_{f} \mathbf{C c}_{\mathbf{m}_{\mathbf{n}}}+\left[P_{f}+F_{f}\right] \mathbf{p}_{\mathbf{m i x}}\left(\mathbf{c}_{\mathbf{m}_{\mathbf{n}}}, \mathbf{c}_{\mathbf{f}_{\mathbf{n}+\mathbf{1}}}\right) \\
& +P_{f} \mathbf{p}_{\mathbf{n}}\left(\mathbf{c}_{\mathbf{f}_{\mathbf{n}+\mathbf{1}}}\right)=0 .
\end{aligned}
$$

The motivation for this is to have a maximum number of terms calculated implicitly while still maintaining symmetry of the element stiffness matrix and avoiding additional degrees of freedom that can not be solved on element level. Although a fully implicit formulation of the system would provide better stability and accuracy of the solution, all variables in the nonlinear system would be unknown (all cell concentrations and tissue fractions in (B.9) and (B.10) would be taken at time point $n+1$ ) and the linearization and subsequent iterations should be performed with respect to all the unknown variables. This would make the stiffness matrix nonsymmetric and not allow the solution of $c_{c}, c_{b}, m_{f}, m_{c}$ and $m_{b}$ on element level. Besides, the presented formulation was successfully tested against an one-dimensional Matlab solution.

Due to the fact that some non-linear terms, namely vectors $\mathbf{p}_{\mathbf{n}}$, include unknown variables, the system is still non-linear. Therefore, the solution is obtained via a Newton scheme. Equations (B.9) and (B.10) are linearized and the linearized system is solved iteratively during the same time step until some convergence criterium is met. The corresponding linearized iterative system is

$$
\left[\begin{array}{cc}
\mathbf{K}_{\mathbf{m}_{\text {stiff }}} & 0 \\
0 & \mathbf{K}_{\mathbf{f}_{\text {stiff }}}
\end{array}\right]\left\{\begin{array}{c}
\delta \mathbf{c}_{\mathbf{m}_{\mathbf{n}+\mathbf{1}}} \\
\delta \mathbf{c}_{\mathbf{f}_{\mathbf{n}+1}}
\end{array}\right\}=\left\{\begin{array}{c}
\mathbf{F}_{\mathbf{I}_{\mathbf{m}}} \\
\mathbf{F}_{\mathbf{I}_{\mathbf{f}}}
\end{array}\right\}
$$

where

$$
\begin{aligned}
\mathbf{K}_{\mathbf{m}_{\text {stiff }}=} & \mathbf{C}+\Delta t\left[\mathbf{K}_{\mathbf{m}}-\left(P_{m}\left[1-c_{c_{n}}-c_{b_{n}}\right]-F_{f}\right.\right. \\
& \left.-F_{c}\left(1-c_{c_{n}}\right)-F_{b}\left(1-c_{b_{n}}\right)\right) \mathbf{C}+\left[P_{m}-F_{f}\right] \\
& \left.\times \frac{\partial \mathbf{p}_{\mathbf{m i x}}\left(\mathbf{c}_{\mathbf{m}_{\mathbf{n}}}, \mathbf{c}_{\mathbf{f}_{\mathbf{n}}}\right)}{\partial \mathbf{c}_{\mathbf{m}_{\mathbf{n}}}}+P_{m} \frac{\partial \mathbf{p}_{\mathbf{n}}\left(\mathbf{c}_{\mathbf{m}_{\mathbf{n}}}\right)}{\partial \mathbf{c}_{\mathbf{m}_{\mathbf{n}}}}\right] \\
\mathbf{K}_{\mathbf{f}_{\text {stiff }}=} & \mathbf{C}+\Delta t\left[\mathbf{K}_{\mathbf{f}}-\left(P_{f}\left[1-c_{c_{n}}-c_{b_{n}}\right]-F_{c}\left(1-c_{c_{n}}\right)\right.\right. \\
& \left.-F_{b}\left(1-c_{b_{n}}\right)\right) \mathbf{C}+\left[P_{f}+F_{f}\right]
\end{aligned}
$$




$$
\begin{aligned}
& \left.\times \frac{\partial \mathbf{p}_{\mathbf{m i x}}\left(\mathbf{c}_{\mathbf{m}_{\mathbf{n}}}, \mathbf{c}_{\mathbf{f}_{\mathbf{n}}}\right)}{\partial \mathbf{c}_{\mathbf{f}_{\mathbf{n}}}}+P_{f} \frac{\partial \mathbf{p}_{\mathbf{n}}\left(\mathbf{c}_{\mathbf{m}_{\mathbf{n}}}\right)}{\partial \mathbf{c}_{\mathbf{f}_{\mathbf{n}}}}\right], \\
\mathbf{F}_{\mathbf{I}_{\mathbf{m}}}= & \mathbf{C} \Delta \mathbf{c}_{\mathbf{m}_{\mathbf{n}}}+\Delta t\left[\mathbf{K}_{\mathbf{m}} \mathbf{c}_{\mathbf{m}_{\mathbf{n}}}-\left(P_{m}\left[1-c_{c_{n}}-c_{b_{n}}\right]\right.\right. \\
& -F_{f}-F_{c}\left(1-c_{c_{n}}\right)- \\
& \left.-F_{b}\left(1-c_{b_{n}}\right)\right) \mathbf{C c}_{\mathbf{m}_{\mathbf{n}}}+\left[P_{m}-F_{f}\right] \\
& \left.\times \mathbf{p}_{\mathbf{m i x}}\left(\mathbf{c}_{\mathbf{m}_{\mathbf{n}}}, \mathbf{c}_{\mathbf{f}_{\mathbf{n}}}\right)+P_{m} \mathbf{p}_{\mathbf{n}}\left(\mathbf{c}_{\mathbf{m}_{\mathbf{n}}}\right)\right], \\
\mathbf{F}_{\mathbf{I}_{\mathbf{f}}}= & \mathbf{C} \Delta \mathbf{c}_{\mathbf{f}_{\mathbf{n}}}+\Delta t\left[\mathbf{K}_{\mathbf{f}} \mathbf{c}_{\mathbf{f}_{\mathbf{n}}}-\left(P_{f}\left[1-c_{c_{n}}-c_{b_{n}}\right]\right.\right. \\
& \left.-F_{c}\left(1-c_{c_{n}}\right)-F_{b}\left(1-c_{b_{n}}\right)\right) \mathbf{C c}_{\mathbf{f}_{\mathbf{n}}}-F_{f} \mathbf{C} \mathbf{c}_{\mathbf{m}_{\mathbf{n}}} \\
& \left.+\left[P_{f}+F_{f}\right] \mathbf{p}_{\mathbf{m i x}}\left(\mathbf{c}_{\mathbf{m}_{\mathbf{n}}}, \mathbf{c}_{\mathbf{f}_{\mathbf{n}}}\right)+P_{f} \mathbf{p}_{\mathbf{n}}\left(\mathbf{c}_{\mathbf{f}_{\mathbf{n}}}\right)\right], \\
\frac{\partial \mathbf{p}_{\mathbf{n}}\left(\mathbf{c}_{\mathbf{i}_{\mathbf{n}}}\right)}{\partial \mathbf{c}_{\mathbf{i}_{\mathbf{n}}}} & =2 \int_{V_{\mathrm{el}}} \mathbf{N}^{\mathbf{T}} \mathbf{N}\left(\mathbf{N}_{\mathbf{i}_{\mathbf{n}}}\right) \mathrm{d} V_{\mathrm{el}}, \quad i=m, f
\end{aligned}
$$$$
\frac{\partial \mathbf{p}_{\mathbf{m i x}}\left(\mathbf{c}_{\mathbf{m}_{\mathbf{n}}}, \mathbf{c}_{\mathbf{f}_{\mathbf{n}}}\right)}{\partial \mathbf{c}_{\mathbf{i}_{\mathbf{n}}}}=\int_{V_{\mathrm{el}}} \mathbf{N}^{\mathbf{T}} \mathbf{N}\left(\mathbf{N c}_{\mathbf{j}_{\mathbf{n}}}\right) \mathrm{d} V_{\mathrm{el}},
$$$$
i=m, f j=f, m \text {. }
$$

As was mentioned before, due to the fact that Eqs. (3)-(7) do not contain any divergence operators, it is quite convenient to solve them on element level, without the need for additional degrees of freedom. Applying the previously mentioned consideration for time discretization to (3) and regrouping the terms around $c_{c_{n+1}}^{2}$ and $c_{c_{n+1}}$, (3) is presented as

$$
\begin{gathered}
\Delta t P_{c} c_{c_{n+1}}^{2}+\left[1-\left(P_{c}\left(1-c_{m_{n}}-c_{f_{n}}-c_{b_{n}}\right)-F_{c}\left(c_{m_{n}}+c_{f_{n}}\right)\right.\right. \\
\left.\left.\quad-F_{b}\left(1-c_{b_{n}}\right)\right) \Delta t\right] c_{c_{n+1}} \\
-\left(F_{c}\left(c_{m_{n}}+c_{f_{n}}\right) \Delta t+c_{c_{n}}\right)=0
\end{gathered}
$$

Using (B.18), $c_{c_{n+1}}$ is calculated during every iteration as a root of a second order equation. In case of a 4-node tetrahedral element, that was developed for this study, we assumed values $c_{c}, c_{b}, m_{b}, m_{c}$ and $m_{f}$ to be constant within the element, while $c_{m}$ and $c_{f}$ are linearly interpolated between the nodes. So, in (B.18) and further $c_{m}$ and $c_{f}$ are the magnitudes, interpolated in the center of the element.

Similarly, osteoblast density, bone, cartilage and fibrous tissue volume fractions are found from the following equations. Osteoblast density $c_{b_{n+1}}$ :

$$
\begin{aligned}
& \Delta t P_{b} c_{b_{n+1}}^{2}+\left[1-\left(P_{b}\left(1-c_{m_{n}}-c_{f_{n}}-c_{c_{n}}\right)\right.\right. \\
& \left.\left.\quad-F_{b}\left(c_{m_{n}}+c_{f_{n}}+c_{c_{n}}\right)\right) \Delta t\right] c_{b_{n+1}} \\
& -F_{b}\left(c_{m_{n}}+c_{f_{n}}+c_{c_{n}}\right) \Delta t-c_{b_{n}}=0,
\end{aligned}
$$

bone matrix volume fraction $m_{b_{n+1}}$ :

$m_{b_{n+1}}=\frac{\Delta t Q_{b} c_{b_{n}}+m_{b_{n}}}{1+\Delta t Q_{b} c_{b_{n}}}$ cartilage volume fraction $m_{c_{n+1}}$ :

$$
\begin{aligned}
& \Delta t D_{b} c_{b_{n}} m_{c_{n+1}}^{2}+\left[1+\Delta t\left(Q_{c} c_{c_{n}}+D_{b} c_{b_{n}}\left(m_{b_{n}}+m_{f_{n}}\right)\right)\right] \\
& \times m_{c_{n+1}}-\left(m_{c_{n}}+\Delta t Q_{c}\left(1-m_{b_{n}}\right) c_{c_{n}}\right)=0, \quad \text { (B.21) }
\end{aligned}
$$

and fibrous tissue volume fraction $m_{f_{n+1}}$ :

$$
\begin{aligned}
& \Delta t\left(D_{b} c_{b_{n}}+D_{c} c_{c_{n}}\right) m_{f_{n+1}}^{2}+\left[1+\Delta t\left(Q_{f} c_{f_{n}}\right.\right. \\
& \left.\left.\quad+\left(D_{b} c_{b_{n}}+D_{c} c_{c_{n}}\right)\left(m_{c_{n}}+m_{b_{n}}\right)\right)\right] m_{f_{n+1}} \\
& \quad-\left(m_{f_{n}}+\Delta t Q_{f}\left(1-m_{c_{n}}-m_{b_{n}}\right) c_{f_{n}}\right)=0 .
\end{aligned}
$$

\section{References}

Ament C, Hofer EP (2000) A fuzzy logic model of fracture healing. J Biomech 33:961-968

Anderson CB (1967) Marks' saturated handbook of mechanical engeneers. Baumeister T (ed). Chapter mechanics of fluids, pp 3.483.76

Andreykiv A (2006) Simulation of bone ingrowth. Ph. D. thesis. Delft University of Technology

Armstrong CG, Mow VC (1982) Variations in the intrinsic mechanical properties of human articular cartilage with age, degeneration and water content. J Bone Joint Surg 64:88-94

Augat P, Burger J, Schorlemmer S, Henke T, Peraus M, Claes L (2003) Shear movement at the fracuture site delays healing in a diaphyseal fracture model. J Orthopaed Res 21:1011-1017

Bailon-Plaza A, van der Meulen M (2003) Beneficial effects of moderate, early loading and adverse effects of delayed or excessive loading on bone healing. J Biomech 36:1069-1077

Bailon-Plaza A, van der Meulen MCH (2001) A mathematical framework to study the effects of growth factors influences on fracture healing. J Theor Biol 212:191-209

Claes L, Augat P, Gebhard S, Wilke H-J (1997) Influence of size and stability of the osteotomy gap on the success of fracture healing. J Orthopaed Res 15(4):577-584

Claes LE, Heigele CA (1999) Magnitudes of local stress and strain along bony surfaces predict the course and type of fracture healing. J Biomech 32:255-266

Claes LE, Heigele CA, Neidlinger-Wilke C, Kaspar D, Seidl W, Margevicius KJ, Augat P (1998) Effects of mechanical factors on the fracture healing process. Clin Orthopaed Rel Res 355:S132S147

Claes LE, Wilke H-J, Augat P, Rübenacker S, Margevicius KJ (1995) Effect of dynamization on gap healing of diaphyseal fracture under external fixation. Clin Biomech 10(5):227-234

Duda GN, Eckert-Hübner K, Sokiranski R, Kreutner A, Miller R, Claes L (1998) Analysis of inter-fragmentary movement as a function of musculoskeletal loading conditons in sheep. J Biomech 31:201210

Einhorn TA (1995) Enhancement of fracuture healing. J Bone Joint Surg 77:940-956

Einhorn TA (1998) The cell and molecular biology of fracture healing. Clin Orthopaed 355:S7-S21

Findlay DM, Welldon K, Atkins GJ, Howie DW, Zannettino ACW, Bobbyn D (2004) The proliferation and phonotypic expression of human osteoblasts on tantalum metal. Biomaterial 25:2215-2227

Friedl P, Zänker KS, Bröcker EB (1998) Cell migration strategies in 3-d extracellular matrix: differences in morphology, cell matrix interections and intergrin function. Microsc Res Tech 43:369378

Garcia-Aznar J, Kuiper J, Gomez-Benito M, Doblare M, Richardson JB (2007) Computational simulation of fracture healing: Influence 
of interfragmentary movement on the callus growth. J Biomech 40:1467-1476

Gardner TN, Stoll T, Marks L, Mishra S, Knothe Tate M (2000) The influence of mechanical stimulus on the pattern of tissue differentiation in a long bone fracture - an fem study. J Biomech 33:415-425

Geris L, Andreykiv A, Van Oosterwyck H, van der Sloten J, van Keulen F, Duyck J, Naert I (2004) Numerical simulation of tissue differentiation around loaded titanium implants in a bone chamber. J Biomech 37:763-769

Gerisch A (2001) Numerical methods for the simulation of taxisdiffusion-reaction systems. Ph.D. thesis, Martin-Luther-Universitat Halle-Wittenberg, Germany

Gerisch A, Chaplain M (2005) Robust numerical methods for taxis diffusion-reaction systems: applications to biomedical problems. Math Comput Model 43:49-75

Goodship AE, Cunningham JL, Kenwright J (1998) Strain rate and timing of stimulation in mechanical modulation of fracture healing. Clin Orthopaed Rel Res 355:S105-S115

Goodship AE, Kenwright J (1985) The influence of induced micromovement upon the healing of experimental tibial fractures. J Bone Joint Surgery 67-B(4):650-655

Gruler H, Bültmann BD (1984) Analysis of cell movement. Blood Cells 10:61-77

Heino TJ, Hentunen TA, Väänänln HK (2004) Conditioned medium from ostocytes stimulates the proliferation of bone marrow mesenchymal stem cells and their diffe. Exp Cell Res 294:458-468

Hori RY, Lewis JL (1982) Mechanical properties of the fibrous tissue found at the bone cement interface following total joint replacement. J Biomed Mater Res 16:911-927

Huiskes R, van Driel WD, Prendergast PJ, Søballe K (1997) A biomechanical regulatory model for periprosthetic fibrous-tissue differentiation. J Mater Sci 8:785-788

Joyce ME, Roberts AB, Sporn MB, Bolander ME (1990) Transforming growth factor- $\beta$ and the initiation of chondrogenesis and osteogenesis in the rat femur. J Cell Biol 110:2195-2207

Kapur S, Baylink DJ, William Lau K-H (2003) Fluid flow shear stress stimulated human osteoblast proliferation and differentiation through multiple interacting and competing signal transduction pathways. Bone 32:241-251

Kaspar D, Seidl W, Neidlinger-Wilke C, Beck A, Claes L, Ignatius A (2002) Proliferation of human-derived osteoblast-like cells depends on the cycle number and frequency of uniaxial strain. J Biomech 35:873-880

Kaspar D, Seidl W, Neidlinger-Wilke C, Ignatius A, Claes L (2000) Dynamic cell stretching increases human osteoblast proliferation and cicp synthesis but decreases osteocalcin synthesis and alkaline phosphatase activity. J Biomech 33:45-51

King JA, Marker PC, Seung KJ, Kingsley DM (1994) Bmp-5 and the molecular, skeletal, and soft-tissue alterations in short ear mice. Develop Biol 166:112-122

Kocher MS, Shapiro F (1998) Osteogenesis imperfecta. J Am Acad Orthopaed Surg 6:225-236

$\mathrm{Ku}$ C-H, Johnson PH, Batten P, Sarathchandra P, Chambers R, Taylor PM, Yacoub MH, Chester AH (2006) Collagen synthesis by mesenchymal stem cells and aortic valve interstitial cells in response to mechanical stretch. Cardiovasc Res 71:548-556

Lacroix D, Prendergast PJ (2002a) A mechano-regulation model for tissue differentiation during fracture healing: analysis of gap size and loading. J Biomech 35(9):1163-1171

Lacroix D, Prendergast PJ (2002b) Three-dimensional simulation of fracture repair in the human tibia. Comput Methods Biomech Biomed Eng 5(5):369-376

Lacroix D, Prendergast PJ, Li G, Marsh D (2002) Biomechanical model to simulate tissue differentiation and bone regeneration: application to fracture healing. Med Biol Eng Comput 40:14-21
Le AX, Miclau T, Hu D, Helms JA (2001) Molecular aspects of healing in stabilized and non-stabilized fractures. J Orthopaed Res 19:7884

Lee TM, Chang E, Yang CY (2004) Attachment and proliferation of neonatal rat calvarial osteoblasts on ti6a14v: effect of surface chemistries of the alloy. Biomaterials 25:23-32

Levick JR (1987) Flow through interstitium and other fibrous matrices. Quart J Exp Physiol 72(4):409-437

Loboa EG, Beaupré GS, Carter DR (2001) Mechanobiology of initial pseudarthrosis formation with oblique fractures. J Orthopaed Res 19:1067-1072

Mizuno S, Watanabe S, Takagi T (2004) Hydrostatic fluid pressure promotes cellularity and proliferation of human dermal fibroblasts in a three-dimensional collagen gel/sponge. Biochem Eng J 20:203208

Ochoa JA, Hillberry BM (1992) Permeability of bovine cancellous bone. In: Transactions of the 38th ORS meeting, vol 162

Perren SM (1979) Physical and biological aspects of fracture healing with special reference to internal fixation. Clin Orthopaed 136:175-196

Praemer A, Furner S, Rice DP (1999) Musculoskeletal conditions in the United States. American Academy of Orthopaedic Surgeons, Rosemount, IL

Prendergast PJ, Huiskes R, Søballe K (1997) Biophysical stimuli on cells during tissue differentiation at implant interfaces. J Biomech 30(6):539-548

Rubin CT, Lanyon LE (1984) Regulation of bone formation by applied dynamic loads. J Bone Joint Surgery Am 66:397-402

Simmons CA, Matlis S, Thornton AJ, Chen S, Wang CY, Mooney DJ (2003) Cyclic strain enhances matrix mineralization by adult human mesenchymal cells via the extracellular signal-regulated kinase (erk1/2) signaling pathway. J Biomech 36:1087-1096

Song G, Ju Y, Shen X, Luo Q, Shi Y, Qin J (2007) Mechanical stretch promotes proliferation of rat bone marrow mesenchymal stem cells. Coll Surf B 58:271-277

Spilker RL, Suh J-K, Mow VC (1988) A finite element formulation of the nonlinear biphasic model for articular carilage and hydrated soft tissues including strain-dependent permeability. Computational methods in bioengineering. Americal Society of Mechanical Engineers, New York, pp. 81-92

Thompson Z, Miclau T, Hu D, Helms JA (2002) A model for intramembranous ossefication during frature healing. J Orthopaed Res 20:1091-1098

Ushida T, Uemura T, Tateishi T (2001) Changes in cell proliferation, alkaline phosphatase activity and CAMP production by mechanical strain in osteoblast-like cells differentiated from rate bone marrow. Mater Sci Eng C 17:51-53

Weyts FAA, Bosmans B, Niesing R, van Leeuwen JPTM, Weinans H (2003) Mechanical control of human osteoblast apoptotis and proliferation in relation to differentiation. Calcified Tissue Int 72:505-512

Wu Q-Q, Chen Q (2000) Mechanoregulation of chondrocyte proliferation, maturation, and hypertrophy: Ion-channel dependent transduction of matrix deformation signals. Exp Cell Res 256:383-391

Yang B, Crawford RC, Wang JH-C (2004) Proliferation and collagen production of human patellar tendon fibroblasts in response to cyclic uniaxial stretching in serum-free conditions. J Biomech 37:1543-1550

Zhang Z-J, Huckle J, Francomano CA, Spencer RG (2003) The effect of pulsed low-intensity ultrasound on chondrocyte viability, proliferation, gene expression and matrix production. Ultrasound Med Biol 29(11):1645-1651 